\title{
Neuroendocrine and Metabolic Effects of Low-Calorie and Non-Calorie Sweeteners
}

\begin{abstract}
Eleonora Moriconi ${ }^{1,2}$, Alessandra Feraco ${ }^{1}$, Vincenzo Marzolla ${ }^{1}$, Marco Infante ${ }^{3}$, Mauro Lombardo ${ }^{4}$, Andrea Fabbri ${ }^{3}$ and Massimiliano Caprio ${ }^{1,4 *}$

${ }^{1}$ Laboratory of Cardiovascular Endocrinology, IRCCS San Raffaele Pisana, Rome, Italy, ${ }^{2}$ Section of Medical Pathophysiology, Food Science and Endocrinology, Department of Experimental Medicine, Sapienza University of Rome, Rome, Italy, ${ }^{3}$ Unit of Endocrinology and Metabolic Diseases, Department of Systems Medicine, CTO A. Alesini Hospital, University of Rome Tor Vergata, Rome, Italy, ${ }^{4}$ Department of Human Sciences and Promotion of the Quality of Life, San Raffaele Roma Open University, Rome, Italy
\end{abstract}

Since excessive sugar consumption has been related to the development of chronic metabolic diseases prevalent in the western world, the use of sweeteners has gradually increased worldwide over the last few years. Although low- and non-calorie sweeteners may represent a valuable tool to reduce calorie intake and prevent weight gain, studies investigating the safety and efficacy of these compounds in the short- and long-term period are scarce and controversial. Therefore, future studies will need to elucidate the potential beneficial and/or detrimental effects of different types of sweeteners on metabolic health (energy balance, appetite, body weight, cardiometabolic risk factors) in healthy subjects and patients with diabetes, obesity and metabolic syndrome. In this regard, the impact of different sweeteners on central nervous system, gut hormones and gut microbiota is important, given the strong implications that changes in such systems may have for human health. The aim of this narrative review is to summarize the current evidence for the neuroendocrine and metabolic effects of sweeteners, as well as their impact on gut microbiota. Finally, we briefly discuss the advantages of the use of sweeteners in the context of very-low calorie ketogenic diets.

Keywords: body weight, microbiota, safety, obesity, diabetes, sugar, metabolic health, VLCKD

\section{INTRODUCTION}

On the basis of their energy content, sweeteners can be classified into calorie, low-calorie and non-calorie compounds. Calorie-sweeteners include natural sugars (1), such as sucrose, glucose, fructose, maltose, lactose, and trehalose. They are mainly present in fruits, honey, milk, dairy products, and mushrooms (2) and their caloric values is on average $4 \mathrm{kcal} / \mathrm{g}$. Their sweetening power is measured in relation to sucrose, which is considered as a reference sugar (3). Low calorie and non-calorie sweeteners provide no or few calories and are characterized by a high sweetness taste. Low-calorie sweeteners include polyols or sugar alcohols, which are low-digestible compounds obtained from the replacement of an aldehyde group with a hydroxyl one (4). The most common polyols are sorbitol, xylitol, maltitol, mannitol, erythritol, isomalt, and lactitol; they are naturally found in fruits, vegetables, and mushrooms (5). Non-calorie sweeteners are mostly obtained by chemical synthesis (except Stevia rebaudiana), and are characterized by minimal or absent nutritional content (3). They include saccharin, aspartame, acesulfame-k, and sucralose (6). 
In the last few decades, intake of sugar (free and added sugars) is dramatically increased, especially in western world (7). High intake of sugars has been related to the development of several diseases, including obesity, type 2 diabetes, cardiovascular disease, non-alcoholic fatty liver disease (8-10), as well as tooth decay (11), neurocognitive diseases (12), and chronic inflammatory disorders (13).

In 2015, the World Health Organization (WHO) recommended the consumption of free sugars below $10 \%$ of total daily energy intake. However, a further reduction in free sugars intake below $5 \%$ of total energy intake has been strongly suggested (14). For a healthy adult, 5\% of total energy intake is equivalent to $\sim 25 \mathrm{~g}$ of sugar per day. Free sugars include all sugars added to foods by the manufacturer, as well as sugars naturally present in non-intact fruit and vegetables (i.e., juiced or pureed). Free sugars do not include sugars naturally present in intact fruit, vegetables, and dairy products (15).

With regard to children and adolescents, a scientific statement published by the American Heart Association (AHA) in 2017 recommends $<25 \mathrm{~g}$ of added sugars per day, although added sugar should not be included in the diet for children $<2$ years of age (16). According to a recent study, in UK added or free sugar intake has been estimated between $7 \%$ and $13 \%$ of total energy intake, respectively, and it is higher in children than in adults (17). The prevalence of obesity and its comorbidities (such as type 2 diabetes, cardiovascular diseases and cancer) has dramatically increased (18) and several governments started to promote policies aimed to encourage a healthy diet and lifestyle (19). In 2011 Denmark introduced a tax on saturated fat, which was repealed in 2012, since it demonstrated a positive but not consistent effect on health (20). In the same year, Hungary added levy on foods with high fat, sugar, salt and caffeine content; soft drinks and alcohols were also taxed. In 2012, France introduced a tax on sweetened beverages $(21,22)$. In United States, where sweetened beverages consumption is still high, taxes on sugarsweetened beverages have been approved since $2014(23,24)$. In California, the first state which approved the tax, a $21 \%$ reduction of sweetened beverage consumption was reported (25) and a positive impact on health care cost savings was observed (26). Since 2016, UK approved several policies in order to reduce childhood obesity, including the "sugar tax" on sweetened beverages, called the Soft Drinks Industry Levy, which became effective in April 2018 (27). In Hungary, sugar tax resulted in a qualitative improvement and reformulation of food products $(28,29)$.

In addition, nutrition labeling has been encouraged in order to help consumers to choose healthy foods. In 2013, the Food Standards Agency in the UK promoted a color coding in labeling system. In this color coding system, red, yellow, and green labels correspond to high, medium, and low percentages of fat, salt, sugar, and total energy present in the product, respectively (30). In this regard, some studies found that front-of-package nutrition labels can readily convey to consumers key information on the nutritional profile of different food products, showing that green labels are associated with the highest healthfulness perception of these products (31). However, Vasiljevic et al. found that nutritional labels of snack foods had limited impact on perceptions of healthiness and no effects on the snack choice, whereas emoticon labels had stronger effects on perceptions of taste and healthfulness of snacks compared to color labels (32).

A recent Cochrane Review evaluated the effects exerted in the general population by the taxation of unprocessed sugar or sugar added foods in terms of consumption of these foods and changes in prevalence and incidence of overweight, obesity, and other diet-related diseases (33). The authors concluded that there is still limited (and low-quality) evidence to support that taxing unprocessed sugar or sugar added foods has a significant impact on reducing their consumption and preventing overweight, obesity or other adverse health outcomes (33). Therefore, future studies are needed to draw concrete conclusions in this direction. Notably, an article by Fernandez and Raine (34) recently reviewed the impact of sugar-sweetened beverage taxation on obesity, concluding that current evidence is still limited. Importantly, authors suggest that sugar-sweetened beverage taxation will likely fail to have a significant impact on the prevalence of obesity and associated non-communicable diseases until this policy will not be associated with interventions aimed to increase access to non-sweetened beverages, educate consumers about healthy beverage alternatives and explore taxation of other beverages and non-nutritive foods (34).

To address the growing health issue of obesity, sweetener consumption has gradually increased over the last years (3538). Indeed, when used judiciously, non-calorie sweeteners may facilitate reductions in the intake of added sugars, leading to decreased total energy, weight loss, prevention of weight gain and/or subsequent beneficial effects on related metabolic parameters (38). Nonetheless, these potential benefits may not be fully achieved without reductions in total food intake and/or in presence of a compensatory increase in energy intake from other sources (38). In addition, animal and human studies have reported controversial results on the safety of non-calorie sweeteners (39). Besides their potential to reduce daily calorie content, non-calorie sweeteners were reported to potentially display detrimental metabolic (weight gain) (40) and neuroendocrine (addiction) effects (41). Conversely, some intervention studies reported that consumption of non-calorie sweeteners is associated with weight loss and improved metabolic parameters $(42,43)$. Despite a growing use of non-calorie sweeteners, which is gradually increasing in both healthy and obese/overweight individuals, there is indeed a knowledge gap regarding their safety and efficacy in the long term-period. Therefore, there is an urgent need to update the current positions from international agencies on the use of these compounds.

We will review here the metabolic and neuroendocrine properties of the most commonly used low-calorie (polyols) and non-calorie sweeteners, along with their safety profile and main use in food industry.

\section{LOW-CALORIE SWEETENERS (POLYOLS OR SUGAR ALCOHOLS)}

Sugar alcohols (also referred to as polyols) are characterized by a lower calorie content ( 2 to $4 \mathrm{kcal} / \mathrm{g}$ ) (44) than sucrose 
TABLE 1 | Comparative profile of the main calorie sweeteners and low-calorie sweeteners ${ }^{a}$.

\begin{tabular}{|c|c|c|c|c|}
\hline Sweetener & $\begin{array}{l}\text { Glycemic } \\
\text { index }^{b}\end{array}$ & $\begin{array}{c}\text { Caloric value } \\
\text { (kcal/g) }^{\mathrm{c}}\end{array}$ & $\begin{array}{l}\text { Sweetening } \\
\text { power }^{d}\end{array}$ & $\begin{array}{l}\text { EFSA } \\
\text { code }^{\mathrm{e}}\end{array}$ \\
\hline \multicolumn{5}{|l|}{ SUGARS } \\
\hline Glucose & 100 & 4 & 0.75 & \\
\hline Fructose & 23 & 4 & 1.7 & - \\
\hline Sucrose & 65 & 4 & 1 & \\
\hline Lactose & 45 & 4 & 0.15 & \\
\hline Maltose & 105 & 4 & 0.3 & \\
\hline \multicolumn{5}{|c|}{ POLYOLS (SUGAR ALCOHOLS) } \\
\hline Erythritol & 0 & 0.2 & $0.6-0.8$ & E-968 \\
\hline Sorbitol & 9 & 2.7 & $0.5-0.7$ & $E-420$ \\
\hline Mannitol & 0 & 1.6 & $0.5-0.7$ & $E-421$ \\
\hline Xylitol & 13 & 2.4 & 1 & E-967 \\
\hline \multicolumn{5}{|c|}{ CALORIE NATURAL SWEETENERS } \\
\hline Trehalose & $45-50$ & 3.6 & $0.5-0.7$ & - \\
\hline Thaumatin & 0 & 4 & $2,000-2,500$ & E-957 \\
\hline \multicolumn{5}{|c|}{ 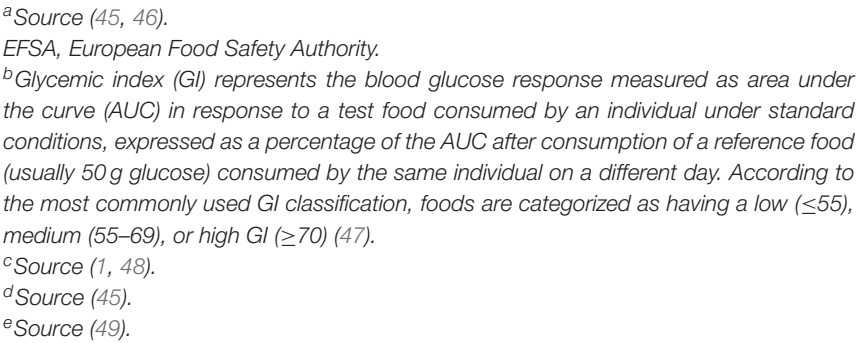 } \\
\hline
\end{tabular}

(Table 1) (45). Low amounts of polyols are naturally present in vegetables, mushrooms and fruits (melon, peach, apple, pear, apricot), but also in oat $(50,51)$. They include hydrogenated mono-, di-, oligo-, and polysaccharides (45) and are mainly used in "sugar-free" products, sweets, and chewing gums (52). Polyols are stable compounds at high temperatures and do not interfere in the Maillard reaction (53). The late stages of Maillard reaction lead to the generation of the so-called AGEs (also referred to as "advanced glycation end-products") in foods and biological systems $(54,55)$. Of note, AGEs contribute to the development of micro- and macrovascular complications of diabetes (5658), by inducing oxidative stress and activating inflammatory pathways $(59,60)$ Polyols do not affect glucose homeostasis $(61,62)$. Also, polyols have long been suggested as valid sugar substitutes able to exert a beneficial role on insulin resistance and glucose control in patients with type 2 diabetes and/or metabolic syndrome. Nonetheless, robust evidence on the longterm effects of polyols in terms of glucose control and chronic complications in diabetic patients is still scarce and inconclusive (45). Interestingly, most of these compounds do not undergo fermentation by oral bacteria flora (63); therefore, polyols can reduce the risk of tooth decay because they represent a poor source of energy to resident bacteria of the oral cavity and do not create an acidic environment $(45,64)$.

Polyols increase saccharolytic anaerobic and aciduric bacteria in the colon and give rise to the production of short-chain fatty acids which play a key role in the maintenance of the intestinal epithelial barrier (45). Although acceptable daily intake (ADI) dose has not been established for polyol increased polyol consumption may cause gastrointestinal discomfort and laxative effects in healthy individuals $(61,64)$. The European Union legislation approved the use of seven different polyols, including erythritol, isomalt, lactitol, maltitol, mannitol, sorbitol, and xylitol (49).

Herein, we summarize the main properties of the polyols that are most commonly used in food and beverage industry, also discussing their potential impact on human health.

\section{Sorbitol (E-420)}

Sorbitol provides $2.6 \mathrm{kcal} / \mathrm{g}$. Sorbitol is naturally present in grapes, prunes, cherries, peaches, apples, pears, and fruit juices (65). Sorbitol is poorly absorbed in the small intestine, while in the colon it is converted by gut microbiota into gases and shortchain fatty acids, providing energy (66). Sorbitol has osmotic effects and it acts as a laxative when ingested in high doses (20$50 \mathrm{~g})$ (67). In addition, chronic ingestion of sorbitol through chewing gums can cause increased intestinal motility regardless of its osmotic effect (68). Therefore, sorbitol use should be avoided by individuals with irritable bowel syndrome (68). In 1993 FDA approved sorbitol use as Generally Recognized As Safe (GRAS) (69).

\section{Mannitol (E-421)}

Mannitol is naturally present in mushrooms, marine algae, strawberries, onions, and pumpkins (70). Only $25 \%$ of ingested mannitol is absorbed in the gut, whereas the remaining part is excreted in the urine. In the gut, mannitol is slowly fermented (45). Mannitol is virtually inert and does not interfere with pharmacological compounds. Due to this reason, it is used also in hygiene products, drug filler and intravenous fluid solutions (53). Moreover, the osmotic diuretic properties of mannitol account for its use as intravenous solution in the management of elevated intracranial pressure and cerebral edema (71).

\section{Xylitol (E-967)}

Xylitol is a natural sweetener found in fruits, vegetables and oats, and it is extracted from birch trees (5). Due to its low caloric content $(2.5 \mathrm{kcal} / \mathrm{g})$ and low glycemic index, xylitol has long been suggested as a valid alternative to glucose and sucrose in patients with diabetes (72). In a pre-clinical study, 4 week administration of xylitol at high doses has been shown to improve glucose tolerance in rats (73). Conversely, a randomized, placebo-controlled, crossover trial conducted in lean and obese volunteers showed that acute xylitol and erythritol ingestion did not significantly affect circulating levels of glucose and insulin, despite being able to stimulate the secretion of the gut hormones cholecystokinin (CCK) and glucagon-like peptide-1 (GLP-1). Of note, the marked increase in CCK and GLP-1 levels was accompanied by a significant slowing in gastric emptying (74). These findings are interesting and do not exclude that chronic ingestion of these sweeteners may play a role in the regulation of glucose homeostasis. Also, the increase in GLP-1 levels may have relevant clinical implications beyond the insulinotropic action 
of GLP-1, considering the well-known role exerted by GLP-1 receptor agonists in the reduction of cardiovascular risk among diabetic patients, along with the anorexigenic properties of GLP1 and its analogs (75-77). Remarkably, CCK has also been shown to induce short-term satiety and to play a role in the regulation of insulin secretion and overall $\beta$-cell function and survival, displaying complementary biological actions with those exerted by GLP-1 (78).

\section{Erythritol (E-968)}

Erythritol is a polyol contained in fruits (e.g., melon, peach), wine and beer (79). It is chemically derived from the fermentation of natural sugars (e.g., glucose and sucrose) by Trichosporonoides megachiliensis (80). Its sweetening power corresponds to $60-$ $80 \%$ of that of sucrose (81). Erythritol is poorly absorbed in the jejunum and is excreted unmodified in the urine (82). Only a small fraction of erythritol undergoes gut fermentation. Therefore, an excessive consumption of erythritol can be associated with laxative effects (83). Gastrointestinal discomfort is generally observed when erythritol intake is $>1,000 \mathrm{mg} / \mathrm{kg}$ of body weight (79). Erythritol intake does not appear to have detrimental effects on glucose control and its use is generally deemed as safe in patients with diabetes (84).

Similarly to other polyols, erythritol does not participate in Maillard-type reactions and, therefore, does not cause the production of AGEs. In addition, by acting as a scavenger for hydroxyl radicals, erythritol exerts anti-oxidant and endothelium-protective properties (83). Erythritol provides a negligible amount of energy $(0.2 \mathrm{kcal} / \mathrm{g})$ (64). Thus, it is commonly used as part of the dietary patterns recommended for people with obesity (85). Due to its sweet taste and high digestive tolerance, and the fact that it is virtually calorie-free and non-cariogenic, erythritol is widely used in the food and beverage industry.

\section{NON-CALORIE SWEETENERS}

Non-calorie sweeteners (also known as artificial sweeteners or non-nutritive sweeteners) are defined as compounds with high sweetening power. Although most of them do not provide calories upon ingestion, some of these compounds (such as aspartame and stevia rebaudiana) have a measurable caloric value that is considered negligible at the doses commonly used by humans.

Non-calorie sweeteners can be of synthetic or natural origin (Table 2).

\section{Stevia Rebaudiana (E-960)}

Stevia rebaudiana has a natural origin. It is commonly called Stevia and derives from a plant that grows in South America (89). Stevia contains steviol glycosides, stevioside, and rebaudioside A, that account for its sweet taste, and other minor glycosides, such as rebaudioside $B$, rebaudioside $C$, rebaudioside $D$, rebaudioside $\mathrm{E}$, rebaudioside $\mathrm{F}$, dulcoside $\mathrm{A}$, rubusoside, and steviolbioside. Stevia also contains a complex of terpenes, tannins, sterols, vitamins, carotenes, flavonoids, and other microelements (90). After ingestion, the steviol glycosides contained in Stevia are
TABLE 2 | Comparative profile of the main non-calorie sweeteners approved by the European Food Safety Authority.

\begin{tabular}{llccc}
\hline Sweetener & $\begin{array}{l}\text { Brand } \\
\text { Names }^{\mathbf{a}}\end{array}$ & $\begin{array}{c}\text { ADI (mg/kg body } \\
\text { weight/day) }^{\mathbf{b}}\end{array}$ & $\begin{array}{c}\text { Sweetening } \\
\text { power }^{\mathbf{c}}\end{array}$ & $\begin{array}{c}\text { EFSA } \\
\text { code }^{\mathbf{d}}\end{array}$ \\
\hline Acesulfame-K & $\begin{array}{l}\text { Sweet One } \\
\text { Sunett }\end{array}$ & 15 & 200 & E950 \\
Aspartame & $\begin{array}{l}\text { Nutrasweet } \\
\text { Equal }\end{array}$ & 40 & 200 & E951 \\
Saccharin & $\begin{array}{l}\text { Sweet and } \\
\text { Low } \\
\text { Sweet Twin }\end{array}$ & 5 & $300-500$ & E954 \\
& $\begin{array}{l}\text { Necta Sweet } \\
\text { Splenda }\end{array}$ & 5 & & \\
Sucralose & Truvia & 4 & $200-300$ & E960 \\
Steviol glycosides & 500 & & E955 \\
\hline
\end{tabular}

$A D I$, Acceptable daily intake.

EFSA, European Food Safety Authority.

a Source $(86,87)$.

bSource $(86,87)$.

c Source $(86,87)$.

'Source (88).

not digested in the upper gastrointestinal tract (91), but they are metabolized by bacteria of the Bacteroidaceae family in the colon, resulting in the production of steviol (92), which is subsequently processed in the liver and converted into steviol glucuronide (93). Energy from fermentation of steviol glycosides (usually assessed as $2 \mathrm{kcal} / \mathrm{g}$ ) is low (92).

Stevia has a strong sweetening power, 200- to 400 -fold higher than that of sucrose (94). Its maximal recommended daily intake is $4 \mathrm{mg} / \mathrm{kg}$, and it is considered unsafe at higher doses (EU regulation 1129/2011) (95). This quantity corresponds to approximately nine tablets per day. Considering that stevia is 200 to 400 times sweeter than sugar, it is extremely unlikely for an individual to ingest the maximum dose of $4 \mathrm{mg} / \mathrm{kg}$ over a $24 \mathrm{~h}$ period. Stevia offers several advantages over other non-calorie sucrose substitutes. In vitro, stevia displayed antiviral effects (96), immunomodulatory activity (97) and antiinflammatory properties, through inhibition of NF- $\kappa \mathrm{B}$ and pro-inflammatory cytokines expression (98). In rats, stevioside showed antihyperglycemic effects through the enhancement of the first-phase of insulin secretion with a concomitant suppression of glucagon levels; stevia also caused a pronounced reduction of both systolic and diastolic blood pressure in rats (99).

Intriguingly, pre-clinical evidence suggests that steviol glycoside derivatives can exert antiproliferative properties in several cancer cell lines, including pancreatic (100), breast (101), and gastric cancer (102) cell lines.

\section{Aspartame (E-951)}

Aspartame was discovered in 1965 (103). It provides $4 \mathrm{kcal} / \mathrm{g}$, but it is included in the group of non-calorie sweeteners, due to its strong sweetening power (104). It is composed by phenylalanine, aspartic acid and methanol (105). Given the high content in phenylalanine, aspartame use is contraindicated in individuals with phenylketonuria, a rare autosomal recessive inborn error 
of metabolism characterized by a decreased metabolism of the amino acid phenylalanine (106).

Although the use of aspartame has been approved in United States since 1974 (107) and in Europe since 1994 (108), its safety is still debated. After several studies performed during the 1970s and the 1980s (109-112), a long term study was carried out in rats to assess its carcinogenic potential (113). Rodents treated with different dosages of aspartame until their natural death showed an increase in the frequencies of lymphomas and leukemias, carcinomas of the renal pelvis and ureter, and schwannomas (114). These results were confirmed even at doses of $20 \mathrm{mg} / \mathrm{kg}$ body weight, which are lower than the recommended maximum daily intake in Europe and in United States (115). The potential carcinogenicity of aspartame was first attributed to methanol, that is converted into formaldehyde and then into formic acid both in rats and humans (116). Based on data obtained from different studies, the European Food Safety Authority (EFSA) was called in 2013 to re-evaluate the safety of aspartame on human health. EFSA concluded that aspartame is safe at a dose of $40 \mathrm{mg} / \mathrm{kg}$ body weight/day (117). However, aspartame safety on human health is still under debate; in fact, a recent study highlighted several important shortcomings in the EFSA document (118).

\section{Acesulfame-K (E-950)}

Acesulfame- $\mathrm{K}$ is a potassium salt of 6-methyl-123-axanthiazine$4(3 \mathrm{H})$-one 2,2 -dioxide. Its sweetening power is 120 -fold higher than sucrose (119). Acesulfame-K does not provide calories. Since it is not catabolized in humans, acesulfame-K does not affect serum potassium levels despite its potassium content (50). The acceptable daily intake (ADI) of acesulfame-K is 15 $\mathrm{mg} / \mathrm{kg}$ body weight. It is used in various sweet foods and beverages (119).

Hydrolysis of acesulfame- $K$ gives rise to acetoacetamide, a degradation product that can be toxic if produced in large amounts (120). Acesulfame-K carcinogenicity has been investigated in rats, where no carcinogenic effects were observed (121). The majority of studies noted that it displays neutral effects on body weight or glucose tolerance $(122,123)$.

\section{Sucralose (E-955)}

Sucralose is derived from sucrose after replacement of three chloride atoms with three hydroxyl groups (124). It was discovered in 1976 and has a sweetening power 450- to 650fold higher than sucrose. The ADI of sucralose is $5 \mathrm{mg} / \mathrm{kg}$ body weight in United States (125) and $15 \mathrm{mg} / \mathrm{kg}$ body weight in Europe (126). Only up to $11-27 \%$ of sucralose is absorbed in the gastrointestinal tract, while the remaining undergoes intestinal excretion unmodified (127). Sucralose is stable during baking and it is considered safe in beverages and foods that require cooking (128). Sucralose consumption does not affect glycemic control or insulin sensitivity in healthy individuals when administered alone, whereas its use in combination with carbohydrates showed a negative impact on glucose metabolism (129).
Several studies in vitro $(130,131)$ and in vivo $(132,133)$ demonstrated that sucralose is not a carcinogenic compound. Only two studies noted a positive relationship between sucralose and mutagenic activity. In one, two human colon cancer cell lines (Caco-2 and HT-29) and one human embryonic kidney cell line (HEK-293) were exposed to very high doses of sweetener solutions for up to 24,48 , and $72 \mathrm{~h}$, leading to cell alterations and DNA fragmentation (134). In the other, mouse lymphoma cells showed doubtful results when exposed to $10 \mathrm{mg} / \mathrm{ml}$ sucralose concentrations (131). However, in both studies very high sucralose concentrations were used. Recently, Soffritti et al. raised questions regarding sucralose safety (135), although EFSA revaluation judged that these results were not supported by the available data (136).

\section{Saccharin (E-954)}

Saccharin is a non-calorie sweetener derived from 1,2benzoisothiazol 3-(2H). Its sweetening potency is almost 300 -fold higher than that of sucrose. Saccharin has an unpleasant bitter or metallic taste (106). Experiments conducted in the 1980s have showed a link between saccharin and an increased incidence of bladder cancer in a rat strain genetically susceptible to bladder tumors, when exposed to $5 \%$ saccharin in the diet for 52 weeks (137). Nonetheless, saccharin generates a urinary precipitate mainly composed of calcium phosphate, which can exert cytotoxic effects on urothelial cells of rats and induce mild hyperplasia (138). However, very high saccharin concentrations were tested in animal models, if compared to the doses commonly ingested by humans (139). With regard to metabolic parameters, a recent study evaluated the administration of saccharin (at different doses, namely: 2.5, 5, and $10 \mathrm{mg} / \mathrm{kg}$ ) in male Wistar rats (140). An increased body weight was noted in rats after 60 and 120 days of $5 \mathrm{mg} / \mathrm{kg}$ saccharin treatment. Authors also observed an increase in glucose, uric acid and creatinine levels, as well as in oxidative status in the liver of saccharin-treated rats, suggesting that saccharin may impair glucose homeostasis, induce obesity and lead to impairments in kidney and liver function (140). The World Health Organization and the EU Scientific Committee for Food declared saccharine as safe up to the approved daily intake doses $(5 \mathrm{mg} / \mathrm{kg}$ body weight) (53). Nowdays, saccharine is commonly used in soft drinks, baked foods, jams, canned fruit, candy, dessert toppings, and chewing gum (141).

\section{IMPACT OF SWEETENERS ON CENTRAL NERVOUS SYSTEM AND METABOLIC OUTCOMES}

The consequences of low-calorie and non-calorie sweeteners on daily food consumption and eating behavior are still controversial. Eating causes an amplification of dopamine release in the nucleus accumbens, similar to what occurs upon substance abuse (142). However, the ingestion of palatable foods causes an increase in dopamine production greater than standard food (143). Given that palatable foods stimulate the same neural pathways involved in drug addiction, it has been suggested that 
an excessive sugar intake can lead to addiction. Moreover, after long-term consumption of sugar, withdrawal symptoms have been described in rats, similarly to what has been observed in morphine and nicotine dependence (144). Food addiction leads to changes in the expression of dopamine receptors (145). Neuroimaging studies revealed that obese individuals exhibit lower dopamine sensitivity in nucleus accumbens accompanied by a decrease in dopamine D2 receptor expression, similar to what has been observed in drug-addicted subjects (146149). Interestingly, dopamine D2 receptor expression is inversely related to body mass index in obese patients (150). These findings suggest that chronic exposure to sugar decreases dopamine-D2 receptor expression. Furthermore, it has been hypothesized that obese subjects respond to dopamine deficiency by overeating palatable foods (151).

Several brain regions are involved in food-reward, namely: lateral hypothalamic area (LHA), ventral tegmental area (VTA), nucleus accumbens (NAc) and prefrontal cortex (PFC). Several neurotransmitters (GABA, glutamate and opioids) are involved in different aspects of reward in the above-mentioned brain regions (152, 153). In particular, the dopaminergic circuitry from LHA to VTA and from VTA to the NAc is involved in hedonic processes ("liking"), reinforcement ("learning"), and motivation ("wanting") (154), while acetylcholine is involved in the aversive aspects of withdrawal (155). During withdrawal state, extracellular dopamine decreases in the accumbens, while acetylcholine is released from accumbens neurons. Intermittent or excessive sugar consumption induces neurochemical modifications, mimicking the effects of opioids (144). Food choice and food intake are physiologically regulated by metabolic and neural signals. In particular, metabolic signals act as nutritional status sensors and mediate the ingestion of a sufficient amount of energy. On the other hand, sensory signals regulate food choice and are linked to subsequent metabolic adaptation, resulting in conditioned responses to these foods (156). The combination of learned responses with metabolic and sensory signals results in a specific pattern of food intake. The responses to sensory inputs, such as taste, texture, and sight of food, include consecutive preabsorptive physiological responses, which are collectively referred to as cephalic phase responses. Such digestive preparation confers to the body the ability to anticipate the particular challenge a food poses for maintaining energy homeostasis (157). Among these responses, the cephalic-phase insulin response, elicited by sugars, enhances glucose tolerance in humans (158-160).

Although replacing calorie with non-calorie sweeteners definitely reduces the energy density of foods and beverages, this does not necessarily translate into metabolic advantages and improved health status. It has been hypothesized that daily intake of non-calorie sweeteners can "trick" the brain by encouraging sugar craving and addiction (161). Indeed, lack of calories generally abolishes the post-ingestive food reward mediated by the hypothalamus (162). In keeping with this, it has been suggested that uncoupling sweet taste from energy causes progressive weakening of conditioned responses to sweet taste (163). As previously mentioned, sweet taste is able to evoke physiological adaptations which play an important role in the finely-tuned regulation of energy homeostasis, by sensing the presence of caloric nutrients in the gut and facilitating the absorption and subsequent utilization of energy. When sweeteners are not associated with caloric intake, their ability to sense energy is altered, with a subsequent reduced ability to use energy and a mitigated activation of the peripheral and central pathways that promote the feeling of satiety (163).

It is also known that non-calorie sweeteners evoke different brain responses compared to calorie sugars. In particular, sucralose is known to display reduced ability to activate midbrain areas related to reward, including LHA, VTA, and NAc (164). Indeed, given the critical role of melanin-concentrating hormone $(\mathrm{MCH})$ neurons in the LHA in establishing nutrient preference, a preclinical study showed that sucrose activated $\mathrm{MCH}$ neurons, resulting in dopamine release (DA). By contrast, sucralose was able to induce DA release in mice only in the presence of light stimulation, which led to the activation of $\mathrm{MCH}$ neurons. These findings suggest that non-calorie sweeteners require additional stimuli to obtain the same rewarding effect of sucrose (Figure 1) (165).

Significant controversy exists over the effects of low-calorie sweeteners on metabolic health. Studies conducted on rodents (166) and humans reported a positive association of low-calorie sweetener consumption with weight gain and/or diabetes (167169), other studies a positive association with lower BMI and weight loss $(170,171)$, in other cases their use was not related to metabolic parameters $(42,43)$. Such heterogeneity is probably due to methodological limitations of some of these studies (172).

A recently published study shed some light on the controversy regarding the effects of low- and non-calorie sweeteners on metabolic health (129). Authors reported that consumption of sucralose was able to rapidly impair glucose metabolism and brain response to sweet taste in healthy subjects only when administered in the presence of carbohydrates. In fact, insulin sensitivity as well as neural responses to sugar were not altered by sucralose or carbohydrate alone. Notably, the combined effect of sucralose and carbohydrates was even more pronounced in adolescents, who showed a dramatic increase in insulin resistance measured by the Homeostatic Model Assessment for Insulin Resistance index (HOMA-IR). These findings refute the "sweet uncoupling hypothesis," which is based on the concept that uncoupling sweet taste from caloric content could determine metabolic dysfunctions and reduce the potency of sweet taste (129).

These data may help explaining the obesogenic potential of low-calorie sweeteners in the context of western diets, especially considering the frequent use of "diet drinks," often containing non-calorie sweeteners, associated with carbohydrates-rich meals.

\section{EFFECTS OF SWEETENERS ON GUT HORMONES}

The sweet taste perception begins with the activation of taste receptors of the tongue, which are located within the taste buds of lingual papillae (173). Taste receptors include G protein-coupled 


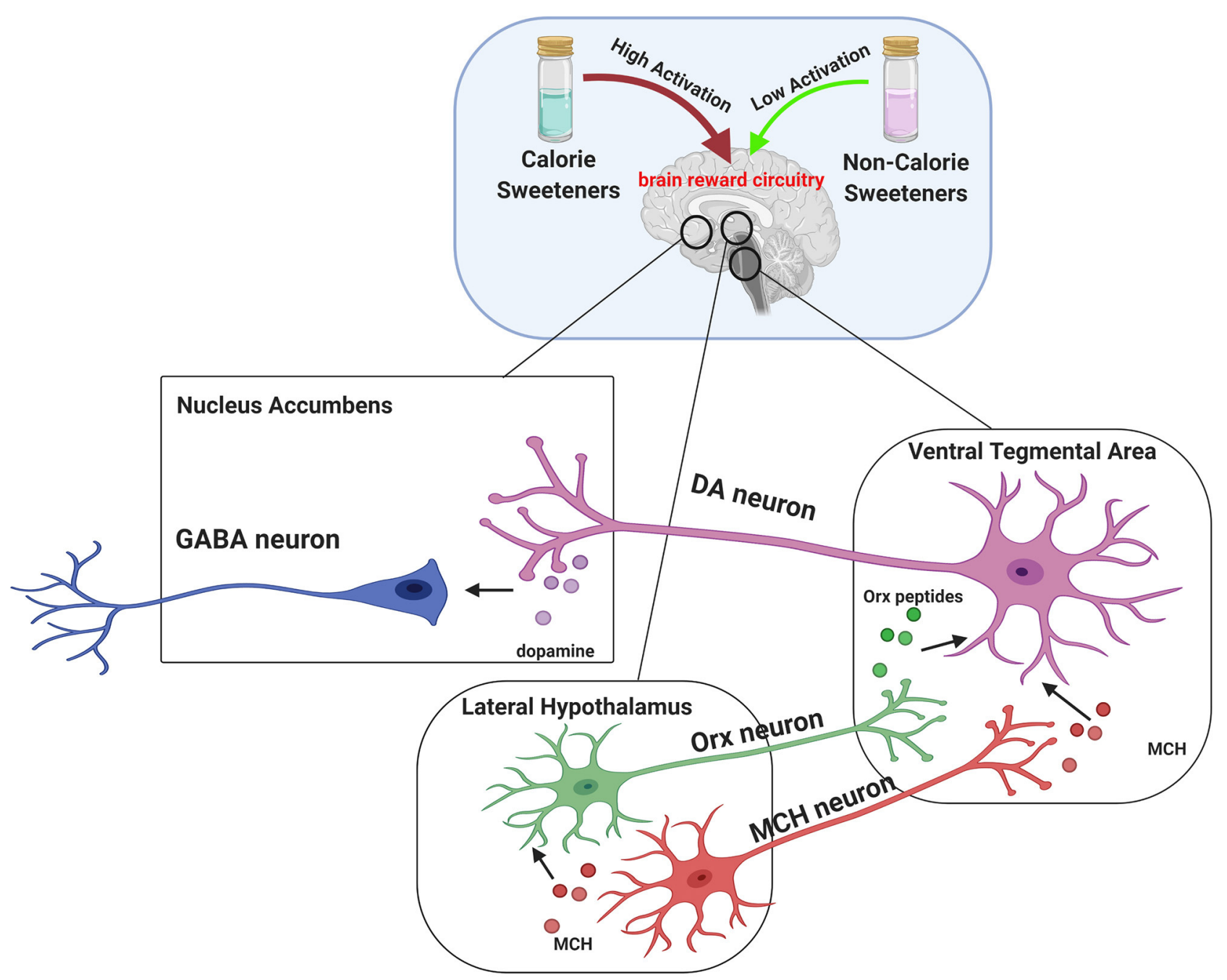

FIGURE 1 | Brain reward circuitry involved in central effects of sweeteners. The dopaminergic pathway is strictly involved in hedonic processes ("liking"), reinforcement ("learning"), and motivation ("wanting"). Midbrain dopaminergic circuits include Lateral Hypothalamus (LHA), Ventral Tegmental Area (VTA), and Nucleus Accumbens (NAc). Dopamine release is driven by orexin (ORX) peptides and melanin-concentrating hormone (MCH) secreted by LHA. In particular, ORX and MCH neurons from LHA project to VTA, where Orx peptides and $\mathrm{MCH}$ mediate the activation of dopamine (DA) neurons and increase the release of DA in projection areas such as the NAc. It has been established that dopamine reward pathway response induced by caloric sweeteners consumption, such as sucrose, is greater compared to non-calorie sweetener sucralose. Interestingly, a preclinical study provided evidence that $\mathrm{MCH}$ neurons account for the natural preference for sucrose over sucralose and that such effect can be reversed by stimulating $\mathrm{MCH}$ neurons with light. This suggests that non calorie-sweeteners require additional stimuli to obtain the same rewarding effect of sucrose.

receptors and ion channels. Type 1 taste receptors (T1Rs; sweettaste and umami receptors) and type 2 taste receptors (T2Rs; bitter-taste receptors) are both $G$ protein-coupled receptors $(174,175)$. The activation of these receptors generates second messengers, such as inositol trisphosphate and diacylglycerol, leading to the activation of taste-transduction channels (176). These metabolic pathways project to brain circuits, allowing the appreciation of taste. Sweet-taste receptors are also expressed outside of the oral cavity. They have been found throughout the gastrointestinal tract, particularly in the enteroendocrine $\mathrm{L}$ and $\mathrm{K}$ cells $(177,178)$. Besides the gastrointestinal tract, sweet-taste receptors have also been found in pancreatic $\beta$-cells
(179), bile ducts (180), and lungs (181). In the gut, glucose is absorbed through sodium-dependent glucose cotransporter-1 (SGLT-1) localized on the luminal membrane and the passive glucose transporter 2 (GLUT2) on the basolateral membrane of the enterocyte (182). Glucose binding to sweet-taste receptors present on enteroendocrine cells leads to GLP-1 and peptide YY (PYY) secretion from L-cells, promoting satiety (183). Since both non-calorie and low-calorie sweeteners bind to sweet-taste receptors present in the oral cavity and subsequently lead to the sweet taste perception, it has been hypothesized that noncalorie sweeteners and low-calorie sweeteners may activate the same sweet-taste receptors expressed on enteroendocrine cells, 
promoting gut hormone secretion. In vitro, sucralose has been shown to stimulate GLP-1 secretion from a human L-cell line (NCI-H716 cells) (184) and to increase GLP-1 and glucosedependent insulinotropic peptide (GIP) release in a murine enteroendocrine cell line (182) (Figure 2). However, these results were not confirmed in vivo. Several studies showed no effect of oral sucralose (185), aspartame, and acesulfame-K on GLP1, PYY, ghrelin, or GIP secretion (186). These results have been confirmed also for sucralose administration before a solid meal, which did not elicit any effects on GIP or GLP-1 release (187). Nevertheless, other studies showed controversial results. In fact, non-calorie sweeteners ingested through diet soda have been shown to synergize with glucose to enhance GLP-1 release in healthy subjects, even if it is unclear whether this effect was due to the activation of sweet-taste receptors present on taste buds of lingual papillae and/or enteroendocrine cells, or if it was due to other mechanisms (188). Moreover, non-calorie sweeteners (such as sucralose, acesulfame-K and saccharin) have been shown to increase glucose absorption in the small intestine by up-regulating SGLT1 expression in mice through the activity of enteric neurons (182). Indeed, GLP-1 stimulates the release of neuropeptides, which in turn bind to $G$ protein-coupled receptors (expressed on the basolateral membrane of enterocytes) and induce SGLT1 expression (182). In vivo, these sweeteners displayed the same effects by increasing GLUT2 expression at the level of the apical membrane (189). Giving the ability of non-calorie sweeteners to increase sugar absorption during a meal, it is worth considering their potential implications in terms of metabolic effects. The recent report that simultaneous consumption of sucralose and maltodextrin-derived glucose acutely disrupts glucose tolerance and insulin sensitivity (129) may be a likely consequence of the increased intestinal glucose absorption following the upregulated expression of SGLT1 and/or GLUT2.

In vitro studies demonstrated that sucralose, saccharin, and acesulfame-K stimulate pancreatic $\beta$-cell insulin secretion in the

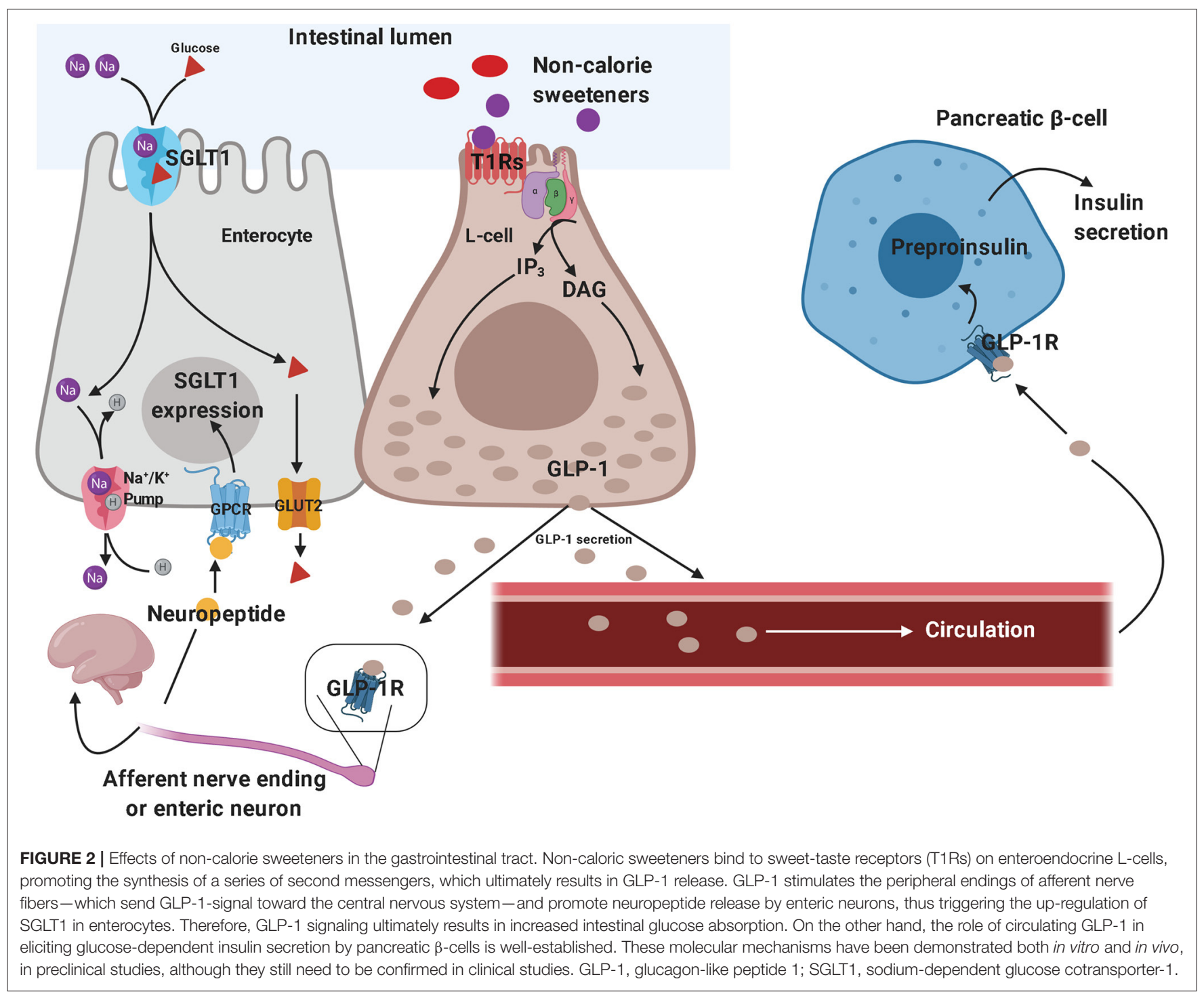


presence of glucose (179). The natural non-calorie sweetener stevia is also able to enhance glucose-induced insulin release, through inhibition of ATP-sensitive K-channels (190) and stevioside has been shown to reduce plasma glucose levels in mice (191), postprandial glucose and glucagon levels in subjects with type 2 diabetes (192). Finally, mechanistics studies are needed to better elucidate the effects of different sweeteners on gut hormone-mediated glucose homeostasis in humans.

Figure 2 depicts some of the effects of non-calorie sweeteners on enteroendocrine cells and gut hormones secretion, which have mainly been inferred from in vitro and animal studies.

\section{IMPACT OF SWEETENERS ON GUT MICROBIOTA}

It has been hypothesized that the relationship between sugar, metabolic syndrome and its related disorders may be mediated, at least in part, by changes in the gut microbiota $(193,194)$. In particular, increased added sugar and novel sweeteners consumption may alter the carbohydrate pools in the gut, thus creating distinct environments that can favor adaptation and enhance colonization and virulence of some endogenous and/or exogenous pathogenic microbes (194).

Since most sugars and sweeteners are absorbed at the level of the small intestine by sugar transporters, only up to $30 \%$ of these compounds reach the large intestine (194). Therefore, the small intestine environment is more enriched in sweeteners compared to large intestine. Moreover, microbes in the small intestine have a greater number of carbohydrate uptake and utilization genes and transcripts compared to those in the large intestine (195).

Gut microbiota composition displays a remarkable spatial heterogeneity across the gastrointestinal tract, with different microbial communities creating distinct microenvironments at different gut locations (a phenomenon also known as "gut biogeography") (196). Di Rienzi and Britton recently proposed that the variation in microbial communities found along the gastrointestinal tract can also depend on the variation in sugars and sweeteners present at different gut locations (194). Furthermore, changes in sugar and sweetener pool can lead to adaptation of the gut microbiota involving transcriptional, metabolic and compositional changes in gut microbes. These changes allow for increase in abundance of microbes whose niche and microenvironment are best filled. In addition, genetic changes can also allow existing microbes to alter their niche in order to better utilize the new nutrient pool (194). Suez et al. demonstrated that saccharin-fed mice developed glucose intolerance as a consequence of compositional and functional alterations to the gut microbiota (197). Similarly, germ-free mice receiving fecal transplantation from saccharin-fed animals displayed glucose intolerance, suggesting that derangements in glucose metabolism are mediated by saccharin-induced alterations to the gut microbiota (197). Similar findings were reproduced in healthy human subjects consuming saccharin for 1 week (197). Importantly, saccharin-fed mice showed a reduction in Akkermansia muciniphila, a mucin-degrading bacteria with probiotic properties associated with favorable metabolic effects
(197). Saccharin consumption has also been shown to affect microbiota composition in rats; the growth of six bacterial strains (three Lactobacillus species and three Escherichia coli strains) was inhibited and the fermentation of glucose was decreased $(198,199)$. Mice treated with saccharin $(0.3 \mathrm{mg} / \mathrm{ml})$ for 6 months showed gut dysbiosis, which is broadly defined as any change in the composition of resident commensal microbial communities relative to the community found in healthy subjects (200), along with an increased expression of pro-inflammatory inducible NO synthase (iNOS) and TNF- $\alpha$ in liver (201).

Sousa et al. clearly demonstrated that a specific diet can alter gut microbiota by changing the abundance of specific strains. Of note, authors inoculated mice with an Escherichia coli strain carrying a mutation disrupting the ability to consume galactitol (a galactose-derived sugar alcohol) (202). Surprisingly, part of the E. coli population regained galactitol metabolism, resulting in the coexistence of two distinct strains within the gut microbiota that could or not consume galactitol (galactitol-positive and galactitol-negative strains, respectively) (202).

Apart from the role of sweeteners as nutrients for gut microbiota, it is worth considering that some of these compounds may exert direct toxict effects on specific microbes. For instance, xylitol cannot be metabolized by oral bacteria (203) and is therefore added to oral products or chewing-gums. Also, stevia glycosides (stevioside and rebaudioside A) have been shown to inhibit the growth of strains of Lactobacillus reuteri, a symbiotic Lactobacillus species which inhabits the gastrointestinal tract of mammals and is often administered as a probiotic additive in healthy foods (204). However, inulin and fructans-contained in the roots of stevia-favored the proliferation of bifidobacteria and lactobacilli in a pre-clinical study (205). Stevia also showed a bactericidal effect on enterohemorrhagic Escherichia coli (206). Also, some sugar alcohols have been shown to promote an increase in the number of beneficial gut microbes both in rats and in healthy human volunteers $(207,208)$. Mice fed a high-fat diet plus xylitol showed a reduced fecal content of Bacteroidetes and Barnesiella, along with an increased abundance of Firmicutes and Prevotella (209). Moreover, xylitol promoted a substantial change in rodent fecal microbiota, decreasing gram-negative and increasing gram-positive bacteria (210).

Of note, the ability of sweeteners to affect gut microbiota composition may also have important immunological implications. In this regard, a recent study conducted on streptozotocin-induced diabetic mice and non-obese diabetic (NOD) mice-which are both widely used as animal models of human type 1 diabetes-has shown that trehalose, a natural caloric disaccharide derived from a rodent intestinal nematode and characterized by antioxidant properties (211), is able to affect gut microbiota by increasing the abundance of Ruminococcus spp. (212). Such change in intestinal microbiota composition appears to account for the induction of CD8+ regulatory $\mathrm{T}$ cells, which play a role in inhibiting the onset of diabetes and reducing blood glucose levels in diabetic animals (212). In addition, authors found that patients with type 1 diabetes, when compared to healthy volunteers, had fewer CD8+ regulatory $\mathrm{T}$ cells, as well as lower serum trehalose concentrations and fecal content of Ruminococcus (212). These results suggest that trehalose may 
have a potential prophylactic and/or therapeutic role in humans (e.g., use of trehalose and Ruminococcus strains as a prebiotic and probiotic, respectively), as a tool to induce CD8+ regulatory $\mathrm{T}$ cells in order to prevent the development of type 1 diabetes and/or counteract the immune-mediated $\beta$-cell destruction shortly after the onset of the disease.

Since sweeteners cross the placenta (213) and are found in the maternal milk (214), there is the potential for a relationship between prenatal exposure to different sweeteners and gut microbiota composition later in life. Animal studies indicate that acesulfame- $\mathrm{K}$ crosses the placenta during pregnancy and can potentially lead to an increased sweet preference during adulthood (215). On the other hand, prenatal sucralose exposure does not affect fetal organogenesis (216), but increases the risk for hematopoietic neoplasia in male mice (135) and favors adipocyte differentation in cultured pre-adipocytes (217). These results suggested that non-calorie sweeteners consumption during pregnancy could impact on offspring adipose tissue differentiation, promoting childhood obesity (217). Moreover, exposure of pregnant mice to a mixture of acesulfame- $K$ and sucralose at different concentrations demonstrated that non-calorie sweeteners were able to affect gut microbiota composition in the offspring in a dose-dependent manner, increasing Firmicutes content and reducing the amount of beneficial species, including Akkermansia muciniphila (218). In conclusion, early prenatal exposure to specific non-calorie sweeteners could favor the occurrence of metabolic diseases later in life, by inducing detrimental changes in the gut microbiota composition.

The aforementioned findings support the notion that sweetener consumption modifies the nutrient environment in the gut and induces a series of functional changes in the gut microbiota, which potentially result in transcriptional, metabolic, compositional, and/or genetic adaptation by gut microbes. In turn, microbial adaptation to sweeteners may affect host-microbe interaction and influence the subsequent immune responses (e.g., pro-inflammatory, anti-inflammatory, immune responses that promote microbe survival or clearance) (194). However, the mechanisms underlying the microbial adaptation to a given sweetener are not fully understood yet. In particular, it is still not clear if dietary sugars and sweeteners can also induce changes in the host environment. The exact impact on the host exerted by microbial metabolites derived from added sugar and sweetener metabolism also needs to be clarified and addressed in future studies.

\section{HEALTH CONCERNS RELATED TO THE USE OF SWEETENERS}

To date, the European Union (EU) and EFSA approved the use of 11 non-calorie sweeteners, namely: acesulfame-K (E-950), advantame (E-969), aspartame (E-951), aspartame-acesulfame salt (E-962), cyclamic acid and its sodium and calcium salts (E-952), neohesperidin dihydrochalcone (E-959), neotame (E961), saccharin (E-954), stevia (E-960), sucralose (E-955), and thaumatin (E-957). EU and EFSA confirmed that non-nutritive and low-calorie sweeteners are safe for human health if used within the ADI (219).

Amongst low-calorie sweeteners, EU approved the following compounds: sorbitol and sorbitol syrup (E420), mannitol (E421), isomaltose (E-953), polyglycitol syrup (E-964), maltitol and maltitol syrup (E-965), lactitol (E-966), xylitol (E-967), and erythritol (E-968).

Unlike non-caloric sweeteners, polyols and low-calorie sweeteners are classified as GRAS and ADI is not reported for them (219). An international consensus statement on the use of low- and non-calorie sweeteners has been signed in Lisbon in July 2017 (220). The Consensus concluded that low- and noncalorie sweeteners consumption is safe, as also supported by WHO, FDA (221) and EFSA (222), and the dietary consumption of low- and non-calorie sweeteners promotes dental health when these compounds replace free sugars $(223,224)$. Therefore, the Consensus encourages the education of consumers on the use of products containing low- and non-calorie sweeteners, in order to increase awareness of general population on their correct use (225).

Finally, consumption of low- and non-calorie sweeteners during pregnancy showed neutral effects on offspring health and data obtained from animal studies were not confirmed in humans (226).

Although more research is needed to fully assess the effects of in utero exposure to sweeteners, current evidence does not suggest adverse effects in pregnancy. Nevertheless, it is recommended that sweeteners are consumed in moderate amounts, adhering to the acceptable daily intake standards established by regulatory agencies (213).

\section{DISCUSSION}

FDA has approved several types of sugar substitutes, considering them as safe. Nonetheless, the American Heart Association and the American Diabetes Association suggest to limit the use of sweeteners due to the lack of strong evidence for their effects on body weight and cardiometabolic risk factors in the long-term period (227).

With regard to effects on gut microbiota, most of the sweeteners affect bacterial gut composition, potentially inducing dysbiosis. Among sweeteners, polyols seem to show a good safety profile. Moreover, they are non-cariogenic, do not negatively affect gut microbiota and are characterized by a very low-energy value (45). Moreover, the potential favorable effects of polyols on glucose homeostasis may suggest their use as a valid option in subjects with type 2 diabetes and metabolic syndrome, although further research is needed in this area.

In this context, a careful nutritional advice is essential for a conscious use and for a correct transition, through the use of sweeteners, from sweetened foods to sugar-free foods. The role of nutrition specialists appears therefore crucial to recommend a diet with a proper use of sweeteners, avoiding the risk of an excessive use of these compounds.

Given the scarcity of data on sweetener safety in the longterm period, it is important to carefully evaluate the use of 
these compounds particularly in selected patients, such as those affected by metabolic derangements. Indeed, different studies and meta-analyses found an association between the consumption of sweeteners and artificially sweetened beverages with increased risk of overweight, obesity, metabolic syndrome and type 2 diabetes $(86,163,228-230)$, thus highlighting the need for future prospective studies aimed at evaluating the exact impact of different types of sweeteners on human health from a metabolic perspective. However, when consumed in moderate amounts, sweeteners may be used as part of a nutritional rehabilitation program aimed to limit daily consumption of refined sugars $(86,163,228-230)$.

Over the last decades several healthy dietary patterns have been proposed to tackle the growing obesity epidemic. Dietary approaches based on marked reduction of carbohydrate and refined sugar consumption are emerging in clinical practice and are highly debated. During the last few years, interest in very low-calorie ketogenic diets (VLCKD) has gradually grown due to their safety and their marked potential in inducing weight loss (231). In this context, non-calorie sweeteners represent a valuable tool for improvement of patient adherence to a strict nutritional regimen and rehabilitation program. The addition of non-calorie sweeteners to food replacements allowed for a marked reduction in carbohydrate and sugar content $(<30 \mathrm{~g} /$ day, $\simeq 13 \%$ of total energy intake), with preservation of food palatability and diet satisfaction (231), thereby avoiding craving and increase in appetite, which may reduce the efficacy of a VLCKD. On the basis of the recent findings on the effects of sucralose (129), the association of non-calorie sweeteners to a very low-carbohydrate nutritional regimen represents a valid approach to prevent the detrimental metabolic effects on insulin sensitivity and the altered neural response to sugars induced by an excessive carbohydrate consumption (Figure 1).

\section{CONCLUDING REMARKS}

Dietary consumption of sweeteners has progressively increased over the last decades in order to reduce the burden of cardiovascular and metabolic diseases caused by modern western diets, which are characterized by a high content in refined and added sugars. Also, the introduction of sugar taxes in several countries is likely to cause an even greater use of these compounds.

Nonetheless, at present there is still scarce evidence to establish conclusively whether the consumption of different types of sweeteners (e.g., low-calorie sweeteners vs. non-calorie sweeteners) can result in significant beneficial or detrimental effects on energy balance, appetite, body weight, and/or cardiometabolic risk factors in healthy subjects and patients with metabolic diseases (particularly obesity and type 2 diabetes). Indeed, the health impact of sweetener consumption, as well as the potential health consequences resulting from switching from one sweetener to another, still remain poorly understood. Therefore, future prospective studies aimed to address short- and long-term safety and efficacy of different types of sweeteners in various clinical settings (e.g., obesity, type 2 diabetes, metabolic syndrome) and in different age groups are needed.

Another area that warrants further investigation is the impact of different types of sweeteners on gut microbiota. Emerging evidence supports how different food components (including sweeteners) can drive changes in the gut microbiota, resulting in relevant implications for human health and disease (86, 194, 230, 232, 233). Mechanistic studies using gut organoids or animal models will certainly help to better elucidate: (i) how different types of sweeteners can reshape the gut microbiota, (ii) the interactions between sweeteners/sweetener metabolites, gut microbiota and host, and (iii) the consequences of these interactions on host physiology and biological processes in the short- and long-term period. Future studies will also be helpful to evaluate which sweeteners are able to promote the growth of beneficial or detrimental gut microbes, resulting in potential human health benefits or harms. Additionally, clinical studies evaluating the impact of different sweeteners on gut microbiota composition will further help to fully address all these unanswered questions regarding the sweetener-gut microbiotahost triad.

Finally, the extent to which all the aforementioned sweetenerinduced changes at different levels (central nervous system circuits, gut hormone secretion and gut microbiota) are clinically relevant in terms of human health is still not clear. Genetic, anthropometric and dietary differences may, at least in part, account for the high interindividual variability in the response to different types of sweeteners (233). Future studies based on epidemiological approaches combined with tools used in precision medicine may help to better establish the subset of individuals who are more likely to receive benefit or harm from sweetener consumption (233).

\section{AUTHOR CONTRIBUTIONS}

All authors listed have made a substantial, direct and intellectual contribution to the work, and approved it for publication. MC and EM conceived, wrote, and revised the manuscript. AFe and VM prepared the figures and wrote part of the manuscript. MI wrote part of the manuscript and carefully revised it. ML and AFa revised the manuscript.

\section{FUNDING}

This paper was funded, in part, by the Italian Ministry of Health (Ricerca Corrente), and by MIUR (Progetti di Ricerca di Interesse Nazionale 2017-Project code 2017ASTXC3-to MC, Work Package Leader).

\section{ACKNOWLEDGMENTS}

We wish to thank Dr. Elisa Fabbrini for critical reading of the manuscript. Figures generation has been performed by using BioRender software. This work is dedicated to the shining memory of Dr. Italo Nosari, and to all other healthcare workers who died of COVID-19. 


\section{REFERENCES}

1. Grembecka M. Natural sweeteners in a human diet. Rocz Panstw Zakl Hig. (2015) 66:195-202.

2. Rippe JM. The health implications of sucrose, high-fructose corn syrup, and fructose: what do we really know? J Diabetes Sci Technol. (2010) 4:100811. doi: $10.1177 / 193229681000400433$

3. Fitch C, Keim KS, Academy of Nutrition and Dietetics. Position of the Academy of Nutrition and Dietetics: use of nutritive and nonnutritive sweeteners. J Acad Nutr Diet. (2012) 112:739-58. doi: 10.1016/j.jand.2012.03.009

4. Billaux MS, Flourie B, Jacquemin C, Messing B. Sugar alcohols. In: Marie S, Piggott JR, editors. Handbook of Sweeteners. Boston, MA: Springer (1991). p. $72-103$.

5. Grembecka M. Sugar alcohols-their role in the modern world of sweeteners: a review. Eur Food Res Technol. (2015) 241:1-14. doi: 10.1007/s00217-015-2437-7

6. Shwide-Slavin C, Swift C, Ross T. Nonnutritive sweeteners: where are we today? Diabetes Spectr. (2012) 25:104-10. doi: 10.2337/diaspect.25.2.104

7. Newens KJ, Walton J. A review of sugar consumption from nationally representative dietary surveys across the world. J Hum Nutr Dietet. (2016) 29:225-40. doi: 10.1111/jhn.12338

8. Luger M, Lafontan M, Bes-Rastrollo M, Winzer E, Yumuk V, FarpourLambert N. Sugar-sweetened beverages and weight gain in children and adults: a systematic review from 2013 to 2015 and a comparison with previous studies. Obes Facts. (2017) 10:674-93. doi: 10.1159/000484566

9. Tappy L. Fructose-containing caloric sweeteners as a cause of obesity and metabolic disorders. J Exp Biol. (2018) 221(Suppl. 1):jeb164202. doi: 10.1242/jeb.164202

10. Jensen T, Abdelmalek MF, Sullivan S, Nadeau KJ, Green M, Roncal C, et al. Fructose and sugar: a major mediator of non-alcoholic fatty liver disease. $J$ Hepatol. (2018) 68:1063-75. doi: 10.1016/j.jhep.2018.01.019

11. Ruxton CHS, Gardner EJ, McNulty HM. Is sugar consumption detrimental to health? A review of the evidence 1995-2006. Crit Rev Food Sci Nutr. (2010) 50:1-19. doi: 10.1080/10408390802248569

12. Pistollato F, Iglesias RC, Ruiz R, Aparicio S, Crespo J, Lopez LD, et al. Nutritional patterns associated with the maintenance of neurocognitive functions and the risk of dementia and Alzheimer's disease: a focus on human studies. Pharmacol Res. (2018) 131:32-43. doi: 10.1016/j.phrs.2018.03.012

13. Johnson RJ, Sánchez-Lozada LG, Andrews P, Lanaspa MA. Perspective: a historical and scientific perspective of sugar and its relation with obesity and diabetes. Adv Nutr. (2017) 8:412-22. doi: 10.3945/an.116.014654

14. Guideline: Sugars Intake for Adults and Children (WHO Guidelines Approved by the Guidelines Review Committee). Geneva: World Health Organization (2015).. Available online at: http://www.ncbi.nlm.nih.gov/ books/NBK285537/

15. Mela DJ, Woolner EM. Perspective: total, added, or free? What kind of sugars should we be talking about? Adv Nutr. (2018) 9:63-9. doi: 10.1093/advances/nmx020

16. Vos MB, Kaar JL, Welsh JA, Van Horn LV, Feig DI, Anderson CAM, et al. Added sugars and cardiovascular disease risk in children: a scientific statement from the american heart association. Circulation. (2017) 135:e1017-34. doi: 10.1161/CIR.0000000000000439

17. Amoutzopoulos B, Steer T, Roberts C, Collins D, Page P. Free and added sugar consumption and adherence to guidelines: the UK National Diet and Nutrition Survey (2014/15-2015/16). Nutrients. (2020) 12:393. doi: 10.3390/nu12020393

18. Martin-Rodriguez E, Guillen-Grima F, Martí A, Brugos-Larumbe A. Comorbidity associated with obesity in a large population: the APNA study. Obes Res Clin Pract. (2015) 9:435-47. doi: 10.1016/j.orcp.2015.04.003

19. Ng M, Fleming $\mathrm{T}$, Robinson $\mathrm{M}$, Thomson B, Graetz N, Margono $\mathrm{C}$, et al. Global, regional, and national prevalence of overweight and obesity in children and adults during 1980-2013: a systematic analysis for the Global Burden of Disease Study 2013. Lancet. (2014) 384:76681. doi: 10.1016/S0140-6736(14)60460-8

20. Vallgårda S, Holm L, Jensen JD. The Danish tax on saturated fat: why it did not survive. Eur J Clin Nutr. (2015) 69:223-6. doi: 10.1038/ejcn.20 14.224
21. Villanueva T. European nations launch tax attack on unhealthy foods. CMAJ. (2011) 183:E1229-30. doi: 10.1503/cmaj.109-4031

22. World Cancer Research Fund International. NOURISHING_Use Economic Tools. World Cancer Research Fund International. (2017). Available online at: http://www.wcrf.org/int/policy/nourishing-framework

23. Rudd Center for Food Policy and Obesity. Legislative Database. (2015) Available online at: http://www.uconnruddcenter.org/legislation-database

24. Paarlberg R, Mozaffarian D, Micha R. Viewpoint: can U.S. local soda taxes continue to spread? Food Policy. (2017) 71:1-7. doi: 10.1016/j.foodpol.2017.05.007

25. Falbe J, Thompson HR, Becker CM, Rojas N, McCulloch CE, Madsen KA. Impact of the Berkeley excise tax on sugar-sweetened beverage consumption. Am J Public Health. (2016) 106:1865-71. doi: 10.2105/AJPH.2016.303362

26. Wilde P, Huang Y, Sy S, Abrahams-Gessel S, Jardim TV, Paarlberg R, et al. Cost-effectiveness of a US National Sugar-Sweetened Beverage Tax with a multistakeholder approach: who pays and who benefits. Am J Public Health. (2019) 109:276-84. doi: 10.2105/AJPH.2018.304803

27. HM Treasury. Soft Drinks Industry Levy Comes into Effect. (2018) Available online at: https://www.gov.uk/government/news/soft-drinks-industry-levycomes-into-effect (accessed December 24, 2018).

28. WHO (World Health Organization). Public Health Product Tax in Hungary: An Example of Successful Intersectoral Action Using a Fiscal Tool to Promote Healthier Food Choices and Raise Revenues for Public Health. (2015).

29. Cawley J, Thow AM, Wen K, Frisvold D. The economics of taxes on sugar-sweetened beverages: a review of the effects on prices, sales, cross-border shopping, and consumption. Ann Rev Nutr. (2019) 39:31738. doi: 10.1146/annurev-nutr-082018-124603

30. Zhang Q, Liu S, Liu R, Xue H, Wang Y. Food policy approaches to obesity prevention: an international perspective. Curr Obes Rep. (2014) 3:171-82. doi: 10.1007/s13679-014-0099-6

31. Schuldt JP. Does green mean healthy? Nutrition label color affects perceptions of healthfulness. Health Commun. (2013) 28:814-21. doi: 10.1080/10410236.2012.725270

32. Vasiljevic M, Pechey R, Marteau TM. Making food labels social: the impact of colour of nutritional labels and injunctive norms on perceptions and choice of snack foods. Appetite. (2015) 91:56-63. doi: 10.1016/j.appet.2015.03.034

33. Pfinder M, Heise TL, Hilton Boon M, Pega F, Fenton C, Griebler $U$, et al. Taxation of unprocessed sugar or sugar-added foods for reducing their consumption and preventing obesity or other adverse health outcomes. Cochrane Database Syst Rev. (2020) 4:CD012333. doi: 10.1002/14651858.CD012333.pub2

34. Fernandez MA, Raine KD. Insights on the influence of sugar taxes on obesity prevention efforts. Curr Nutr Rep. (2019) 8:333-9. doi: 10.1007/s13668-019-00282-4

35. Sylvetsky AC, Welsh JA, Brown RJ, Vos MB. Low-calorie sweetener consumption is increasing in the United States. Am J Clin Nutr. (2012) 96:640-6. doi: 10.3945/ajcn.112.034751

36. Sylvetsky AC, Rother KI. Trends in the consumption of low-calorie sweeteners. Physiol Behav. (2016) 164(Pt. B):44650. doi: 10.1016/j.physbeh.2016.03.030

37. Sylvetsky AC, Jin Y, Clark EJ, Welsh JA, Rother KI, Talegawkar SA. Consumption of low-calorie sweeteners among children and adults in the United States. J Acad Nutr Diet. (2017) 117:441-8.e2. doi: 10.1016/j.jand.2016.11.004

38. Gardner C, Wylie-Rosett J, Gidding SS, Steffen LM, Johnson RK, Reader D, et al. Nonnutritive sweeteners: current use and health perspectives: a scientific statement from the American Heart Association and the American Diabetes Association. Diabetes Care. (2012) 35:1798808. doi: $10.2337 / \mathrm{dc} 12-9002$

39. Tandel KR. Sugar substitutes: health controversy over perceived benefits. $J$ Pharmacol Pharmacother. (2011) 2:236-43. doi: 10.4103/0976-500X.85936

40. Fowler SP, Williams K, Resendez RG, Hunt KJ, Hazuda HP, Stern MP. Fueling the obesity epidemic? Artificially sweetened beverage use and long-term weight gain. Obesity. (2008) 16:1894-900. doi: 10.1038/oby.2008.284

41. Lenoir M, Serre F, Cantin L, Ahmed SH. Intense sweetness surpasses cocaine reward. PLoS ONE. (2007) 2:e698. doi: 10.1371/journal.pone.0000698

42. Raben A, Møller BK, Flint A, Vasilaris TH, Christina Møller A, Juul Holst J, et al. Increased postprandial glycaemia, insulinemia, and 
lipidemia after 10 weeks' sucrose-rich diet compared to an artificially sweetened diet: a randomised controlled trial. Food Nutr Res. (2011) 55. doi: 10.3402/fnr.v55i0.5961

43. Raben A, Vasilaras TH, Møller AC, Astrup A. Sucrose compared with artificial sweeteners: different effects on ad libitum. food intake and body weight after $10 \mathrm{wk}$ of supplementation in overweight subjects. Am J Clin Nutr. (2002) 76:721-9. doi: 10.1093/ajcn/76.4.721

44. FDA. High-Intensity Sweeteners. (2015). Available online at: www.fda.gov/ food/ingredientspackaginglabeling/foodadditivesingredients/ucm397716. $\mathrm{htm}$.

45. Livesey G. Health potential of polyols as sugar replacers, with emphasis on low glycaemic properties. Nutr Res Rev. (2003) 16:163-91. doi: 10.1079/NRR200371

46. Godshall MA. The expanding world of nutritive and non-nutritive sweeteners. Sugar J. (2007) 69:12-20. Available online at: https://eurekamag. com/research/013/046/013046225.php

47. Venn BJ, Green TJ. Glycemic index and glycemic load: measurement issues and their effect on diet-disease relationships. Eur J Clin Nutr. (2007) 61:S122-31. doi: 10.1038/sj.ejcn.1602942

48. Leone A, De Amicis R, Lessa C, Tagliabue A, Trentani C, Ferraris C, et al. Food and food products on the Italian market for ketogenic dietary treatment of neurological diseases. Nutrients. (2019) 11:1104. doi: 10.3390/nu11051104

49. Regulation (EC) no $1333 / 2008$ of the European Parliament and of the Council of 16 December 2008 on food additives. Official Journal of the European Union. OJ L 354, 16-33 p.

50. American Dietetic Association. Position of the American dietetic association: use of nutritive and nonnutritive sweeteners. J Am Diet Assoc. (2004) 104:255-75. doi: 10.1016/j.jada.2003.12.001

51. Gupta M. Sugar substitutes: mechanism, availability, current use and safety concerns-an update. Open Access Maced J Med Sci. (2018) 6:188894. doi: 10.3889/oamjms.2018.336

52. Ruiz E, Rodriguez P, Valero T, Ávila JM, Aranceta-Bartrina J, Gil Á, et al. Dietary intake of individual (free and intrinsic) sugars and food sources in the spanish population: findings from the ANIBES study. Nutrients. (2017) 9:275. doi: 10.3390/nu9030275

53. Carocho M, Morales P, Ferreira ICFR. Sweeteners as food additives in the XXI century: a review of what is known, and what is to come. Food Chem Toxicol. (2017) 107(Pt. A):302-17. doi: 10.1016/j.fct.2017.06.046

54. Chuyen NV. Toxicity of the AGEs generated from the Maillard reaction: on the relationship of food-AGEs and biological-AGEs. Mol Nutr Food Res. (2006) 50:1140-9. doi: 10.1002/mnfr.200600144

55. de Oliveira FC, Coimbra JSDR, de Oliveira EB, Zuñiga ADG, Rojas EEG. Food protein-polysaccharide conjugates obtained via the maillard reaction: a review. Crit Rev Food Sci Nutr. (2016) 56:1108-25. doi: 10.1080/10408398.2012.755669

56. Yozgatli K, Lefrandt JD, Noordzij MJ, Oomen PHN, Brouwer T, Jager $\mathrm{J}$, et al. Accumulation of advanced glycation end products is associated with macrovascular events and glycaemic control with microvascular complications in type 2 diabetes mellitus. Diabet Med. (2018) 35:1242-1248. doi: $10.1111 / \mathrm{dme} .13651$

57. Genuth S, Sun W, Cleary P, Sell DR, Dahms W, Malone J, et al. Glycation and carboxymethyllysine levels in skin collagen predict the risk of future 10-year progression of diabetic retinopathy and nephropathy in the diabetes control and complications trial and epidemiology of diabetes interventions and complications participants with type 1 diabetes. Diabetes. (2005) 54:310311. doi: $10.2337 /$ diabetes.54.11.3103

58. Goh S-Y, Cooper ME. Clinical review: the role of advanced glycation end products in progression and complications of diabetes. J Clin Endocrinol Metab. (2008) 93:1143-52. doi: 10.1210/jc.2007-1817

59. Schmidt AM, Vianna M, Gerlach M, Brett J, Ryan J, Kao J, et al. Isolation and characterization of two binding proteins for advanced glycosylation end products from bovine lung which are present on the endothelial cell surface. J Biol Chem. (1992) 267:14987-97.

60. Tamanna N, Mahmood N. Food processing and maillard reaction products: effect on human health and nutrition. Int J Food Sci. (2015) 2015:16. doi: 10.1155/2015/526762

61. Grabitske HA, Slavin JL. Low-digestible carbohydrates in practice. J Am Diet Assoc. (2008) 108:1677-81. doi: 10.1016/j.jada.2008.07.010
62. Nakamura S. Bioavailability of cellobiose and other non-digestible and/or non-absorbable sugar substitutes and related topics. Nutrition. (2005) 21:1158-9. doi: 10.1016/j.nut.2005.08.006

63. Štšepetova J, Truu J, Runnel R, Nõmmela R, Saag M, Olak J, et al. Impact of polyols on Oral microbiome of Estonian schoolchildren. BMC Oral Health. (2019) 19:60. doi: 10.1186/s12903-019-0747-z

64. EFSA Panel on Dietetic Products, Nutrition and Allergies (NDA). Scientific Opinion on the substantiation of health claims related to the sugar replacers xylitol, sorbitol, mannitol, maltitol, lactitol, isomalt, erythritol, D-tagatose, isomaltulose, sucralose and polydextrose and maintenance of tooth mineralisation by: sugar replacers xylitol, sorbitol, mannitol, maltitol, lactitol, isomalt, erythritol, D-tagatose, isomaltulose, sucralose and polydextrose related hea. EFSA J. (2011) 9:2076. doi: 10.2903/j.efsa.20 11.2076

65. Vaaler S, Bjørneklett A, Jelling I, Skrede G, Hanssen KF, Fausa O, et al. Sorbitol as a sweetener in the diet of insulin-dependent diabetes. Acta Med Scand. (1987) 221:165-70. doi: 10.1111/j.0954-6820.1987.tb01262.x

66. Mortensen PB, Holtug K, Rasmussen HS. Short-chain fatty acid production from mono- and disaccharides in a fecal incubation system: implications for colonic fermentation of dietary fiber in humans. J Nutr. (1988) 118:3215. doi: 10.1093/jn/118.3.321

67. Ravry MJ. Dietetic food diarrhea. JAMA. (1980) 244:270. doi: 10.1001/jama.1980.03310030046027

68. Goldstein R, Braverman D, Stankiewicz H. Carbohydrate malabsorption and the effect of dietary restriction on symptoms of irritable Bowel syndrome and functional bowel complaints. Isr Med Assoc J. (2000) 2:583-7.

69. Modderman JP. Safety assessment of hydrogenated starch hydrolysates. Regul Toxicol Pharmacol. (1993) 18:80-114. doi: 10.1006/rtph.1993.1047

70. Biesiekierski JR, Rosella O, Rose R, Liels K, Barrett JS, Shepherd SJ, et al. Quantification of fructans, galacto-oligosacharides and other short-chain carbohydrates in processed grains and cereals. J Hum Nutr Diet. (2011) 24:154-76. doi: 10.1111/j.1365-277X.2010.01139.x

71. Shawkat H, Westwood M-M, Mortimer A. Mannitol: a review of its clinical uses. Continuing Educ Anaesth Critical Care Pain. (2012) 12:825. doi: 10.1093/bjaceaccp/mkr063

72. Brunzell JD. Use of fructose, xylitol, or sorbitol as a sweetener in diabetes mellitus. Diabetes Care. (1978) 1:223-30. doi: 10.2337/diacare.1.4.223

73. Rahman MA, Islam MS. Xylitol improves pancreatic islets morphology to ameliorate type 2 diabetes in rats: a dose response study. J Food Sci. (2014) 79:H1436-42. doi: 10.1111/1750-3841.12520

74. Wölnerhanssen BK, Cajacob L, Keller N, Doody A, Rehfeld JF, Drewe J, et al. Gut hormone secretion, gastric emptying, and glycemic responses to erythritol and xylitol in lean and obese subjects. Am J Physiol Endocrinol Metab. (2016) 310:E1053-61. doi: 10.1152/ajpendo.00037.2016

75. Caprio M, Vitale C, Rosano GMC. From glucose lowering to treatment of cardiovascular disease: the repositioning of glucose-lowering agents. Eur Heart J Cardiovasc Pharmacother. (2020). doi: 10.1093/ehjcvp/pvaa019. [Epub ahead of print].

76. Sheahan KH, Wahlberg EA, Gilbert MP. An overview of GLP-1 agonists and recent cardiovascular outcomes trials. Postgrad Med J. (2020) 96:15661. doi: 10.1136/postgradmedj-2019-137186

77. Gallwitz B. Anorexigenic effects of GLP-1 and its analogues. Handb Exp Pharmacol. (2012) 2012:185-207. doi: 10.1007/978-3-642-24716-3_8

78. Pathak V, Flatt PR, Irwin N. Cholecystokinin (CCK) and related adjunct peptide therapies for the treatment of obesity and type 2 diabetes. Peptides. (2018) 100:229-35. doi: 10.1016/j.peptides.2017.09.007

79. Bernt WO, Borzelleca JF, Flamm G, Munro IC. Erythritol: a review of biological and toxicological studies. Regul Toxicol Pharmacol. (1996) 24(Pt. 2):S191-7. doi: 10.1006/rtph.1996.0098

80. Lin S-J, Wen C-Y, Wang P-M, Huang J-C, Wei C-L, Chang J-W, et al. High-level production of erythritol by mutants of osmophilic Moniliella sp. Proc Biochem. (2010) 45:973-9. doi: 10.1016/j.procbio.2010. 03.003

81. Grenby TH. Advances in Sweeteners. Boston: Springer (1996).

82. Munro IC, Berndt WO, Borzelleca JF, Flamm G, Lynch BS, Kennepohl E, et al. Erythritol: an interpretive summary of biochemical, metabolic, toxicological and clinical data. Food Chem Toxicol. (1998) 36:113974. doi: 10.1016/S0278-6915(98)00091-X 
83. den Hartog GJM, Boots AW, Adam-Perrot A, Brouns F, Verkooijen IWCM, Weseler AR, et al. Erythritol is a sweet antioxidant. Nutrition. (2010) 26:44958. doi: 10.1016/j.nut.2009.05.004

84. Noda K, Nakayama K, Oku T. Serum glucose and insulin levels and erythritol balance after oral administration of erythritol in healthy subjects. Eur J Clin Nutr. (1994) 48:286-92.

85. Wheeler ML, Pi-Sunyer FX. Carbohydrate issues: type and amount. J Am Diet Assoc. (2008) 108(Suppl. 1):S34-9. doi: 10.1016/j.jada.2008.01.024

86. Liauchonak I, Qorri B, Dawoud F, Riat Y, Szewczuk M. Non-nutritive sweeteners and their implications on the development of metabolic syndrome. Nutrients. (2019) 11:644. doi: 10.3390/nu11030644

87. Purohit V, Mishra S. The truth about artificial sweeteners - are they good for diabetics? Indian Heart J. (2018) 70:197-9. doi: 10.1016/j.ihj.2018.01.020

88. Mortensen A. Sweeteners permitted in the European Union: safety aspects. Scand J Food Nutr. (2006) 50:104-16. doi: 10.1080/17482970600982719

89. Samuel P, Ayoob KT, Magnuson BA, Wölwer-Rieck U, Jeppesen PB, Rogers PJ, et al. Stevia leaf to stevia sweetener: exploring its science, benefits, and future potential. J Nutr. (2018) 148:1186S-205S. doi: 10.1093/jn/nxy 102

90. Carrera-Lanestosa A, Moguel-Ordóñez Y, Segura-Campos M. Stevia rebaudiana bertoni: a natural alternative for treating diseases associated with metabolic syndrome. J Med Food. (2017) 20:933-43. doi: 10.1089/jmf.2016.0171

91. Geuns JMC, Buyse J, Vankeirsbilck A, Temme EHM. Metabolism of stevioside by healthy subjects. Exp Biol Med. (2007) 232:164-73.

92. Gardana C, Simonetti P, Canzi E, Zanchi R, Pietta P. Metabolism of stevioside and rebaudioside a from Stevia rebaudiana extracts by human microflora. $J$ Agric Food Chem. (2003) 51:6618-22. doi: 10.1021/jf0303619

93. Wheeler A, Boileau AC, Winkler PC, Compton JC, Prakash I, Jiang $\mathrm{X}$, et al. Pharmacokinetics of rebaudioside $\mathrm{A}$ and stevioside after single oral doses in healthy men. Food Chem Toxicol. (2008) 46(Suppl. 7):S5460. doi: 10.1016/j.fct.2008.04.041

94. Soejima A, Tanabe AS, Takayama I, Kawahara T, Watanabe K, Nakazawa $\mathrm{M}$, et al. Phylogeny and biogeography of the genus Stevia (Asteraceae: Eupatorieae): an example of diversification in the Asteraceae in the new world. J Plant Res. (2017) 130:953-72. doi: 10.1007/s10265-017-0955-Z

95. EFSA Panel of Food Additive and Nutrient Sources added to Food. European Food Safety Authority Scientific opinion on the safety of the proposed amendment of the specifications for steviol glycosides (E960) as a food additive. EFSA J. (2015) 13:4316. doi: 10.2903/j.efsa.2015.4316

96. Takahashi K, Matsuda M, Ohashi K, Taniguchi K, Nakagomi O, Abe Y, et al. Analysis of anti-rotavirus activity of extract from Stevia rebaudiana. Antiviral Res. (2001) 49:15-24. doi: 10.1016/S0166-3542(00)00134-0

97. Sehar I, Kaul A, Bani S, Pal HC, Saxena AK. Immune up regulatory response of a non-caloric natural sweetener, stevioside. Chem Biol Interact. (2008) 173:115-21. doi: 10.1016/j.cbi.2008.01.008

98. Fengyang L, Yunhe F, Bo L, Zhicheng L, Depeng L, Dejie L, et al. Stevioside suppressed inflammatory cytokine secretion by downregulation of NF$\kappa \mathrm{B}$ and MAPK signaling pathways in LPS-stimulated RAW264.7 cells. Inflammation. (2012) 35:1669-75. doi: 10.1007/s10753-012-9483-0

99. Jeppesen PB, Gregersen S, Rolfsen SED, Jepsen M, Colombo M, Agger A, et al. Antihyperglycemic and blood pressure-reducing effects of stevioside in the diabetic Goto-Kakizaki rat. Metab Clin Exp. (2003) 52:3728. doi: 10.1053/meta.2003.50058

100. Dooley J, Lagou V, Dresselaers T, van Dongen KA, Himmelreich U, Liston A. No effect of dietary aspartame or stevia on pancreatic acinar carcinoma development, growth, or induced mortality in a murine model. Front Oncol. (2017) 7:18. doi: 10.3389/fonc.2017.00018

101. Gupta E, Kaushik S, Purwar S, Sharma R, Balapure AK, Sundaram S. Anticancer potential of steviol in MCF-7 human breast cancer cells. Pharmacogn Mag. (2017) 13:345-50. doi: 10.4103/pm.pm_29_17

102. Chen J, Xia Y, Sui X, Peng Q, Zhang T, Li J, et al. Steviol, a natural product inhibits proliferation of the gastrointestinal cancer cells intensively. Oncotarget. (2018) 9:26299-308. doi: 10.18632/oncotarget.25233

103. Mazur RH, Goldkamp AH, James PA, Schlatter JM. Structure-taste relationships of aspartic acid amides. J Med Chem. (1970) 13:121721. doi: $10.1021 / \mathrm{jm} 00300 \mathrm{a} 046$
104. Jorge K. Soft drinks | chemical composition. In: Encyclopedia of Food Sciences and Nutrition. Elsevier. (2003) p. 5346-52.

105. Ashok I, Sheeladevi R, Wankhar D. Acute effect of aspartame-induced oxidative stress in Wistar albino rat brain. J Biomed Res. (2015) 29:3906. doi: 10.7555/JBR.28.20120118

106. Chattopadhyay S, Raychaudhuri U, Chakraborty R. Artificial sweeteners - a review. I Food Sci Technol. (2014) 51:61121. doi: 10.1007/s13197-011-0571-1

107. FDA (Food and Drug Administration). Food Additives Permitted in Food for Human Consumption: Aspartame (1974).

108. EC Directive 35. Directive 94/35/EC of 30 June 1994 on sweeteners for use in foodstuffs. Offic J L. (1994) 237:3-12.

109. FDA (Food and Drug Administration). Aspartame: Commissioner's Final Decision. Federal Register (1981).

110. Molinary SV. Preclinical studies of aspartame in non primate animals. In: Stegink LD, Filer LJ Jr., editors. Aspartame Physiology and Biochemistry. New York, NY: Dekker (1984). p. 289-306.

111. Ishii H. Incidence of brain tumors in rats fed aspartame. Toxicol Lett. (1981) 7:433-7. doi: 10.1016/0378-4274(81)90089-8

112. Ishii H, Koshimizu T, Usami S, Fujimoto T. Toxicity of aspartame and its diketopiperazine for Wistar rats by dietary administration for 104 weeks. Toxicology. (1981) 21:91-4. doi: 10.1016/0300-483X(81)90119-0

113. Belpoggi F, Soffritti M, Padovani M, Degli Esposti D, Lauriola M, Minardi F. Results of long-term carcinogenicity bioassay on Sprague-Dawley rats exposed to aspartame administered in feed. Ann N Y Acad Sci. (2006) 1076:559-77. doi: 10.1196/annals.1371.080

114. Soffritti M, Belpoggi F, Minardi F, Bua L, Maltoni C. Mega-experiments to identify and assess diffuse carcinogenic risks. Ann N Y Acad Sci. (1999) 895:34-55. doi: 10.1111/j.1749-6632.1999.tb08076.x

115. Soffritti M, Belpoggi F, Degli Esposti D, Lambertini L, Tibaldi E, Rigano A First experimental demonstration of the multipotential carcinogenic effects of aspartame administered in the feed to Sprague-Dawley rats. Environ Health Perspect. (2006) 114:379-85. doi: 10.1289/ehp.8711

116. Ranney RE, Oppermann JA, Muldoon E, McMahon FG. Comparative metabolism of aspartame in experimental animals and humans. J Toxicol Environ Health. (1976) 2:441-51. doi: 10.1080/15287397609529445

117. EFSA Panel on Food Additives and Nutrient Sources added to Food (ANS). Scientific Opinion on the re-evaluation of aspartame (E 951) as a food additive. EFSA J. (2013) 11:3496. doi: 10.2903/j.efsa.2013.3496

118. Millstone EP, Dawson E. EFSA's toxicological assessment of aspartame: was it even-handedly trying to identify possible unreliable positives and unreliable negatives? Arch Public Health. (2019) 77:34. doi: 10.1186/s13690-019-0355-Z

119. Horne J, Lawless HT, Speirs W, Sposato D. Bitter taste of saccharin and acesulfame-K. Chem Senses. (2002) 27:31-8. doi: 10.1093/chemse/27.1.31

120. George V, Arora S, Wadhwa BK, Singh AK. Analysis of multiple sweeteners and their degradation products in lassi by HPLC and HPTLC plates. J Food Sci Technol. (2010) 47:408-13. doi: 10.1007/s13197-010-0067-4

121. National Toxicology Program. NTP toxicology studies of acesulfame potassium (CAS No. 55589-62-3) in genetically modified (FVB Tg.AC Hemizygous) mice and carcinogenicity studies of acesulfame potassium in genetically modified [B6.129-Trp53(tm1Brd) (N5) Haploinsufficient] mice (feed studies)mice. Natl Toxicol Prog Genet Modif Model Rep. (2005) 2:1-113.

122. Chan CB, Hashemi Z, Subhan FB. The impact of low and no-caloric sweeteners on glucose absorption, incretin secretion, and glucose tolerance. Appl Physiol Nutr Metab. (2017) 42:793-801. doi: 10.1139/apnm-201 6-0705

123. Bryant CE, Wasse LK, Astbury N, Nandra G, McLaughlin JT. Non-nutritive sweeteners: no class effect on the glycaemic or appetite responses to ingested glucose. Eur J Clin Nutr. (2014) 68:629-31. doi: 10.1038/ejcn.2014.19

124. Roberts A, Renwick AG, Sims J, Snodin DJ. Sucralose metabolism and pharmacokinetics in man. Food Chem Toxicol. (2000) 38(Suppl. 2):S3141. doi: 10.1016/S0278-6915(00)00026-0

125. US Food and Drug Administration (US FDA). Food Additives Permitted For Direct Addition to Food for Human Consumption; Sucralose (1998).

126. European Union. Directive 2003/115/EC of the European Parliament and of the Council of 22 December 2003 Amending Directive 94/35/EC on Sweeteners for Use in Foodstuffs. Office Journal European Union 47 (2004). 
127. Knight I. The development and applications of sucralose, a new high-intensity sweetener. Can J Physiol Pharmacol. (1994) 72:4359. doi: $10.1139 / \mathrm{y} 94-063$

128. Grotz VL, Munro IC. An overview of the safety of sucralose. Regul Toxicol Pharmacol. (2009) 55:1-5. doi: 10.1016/j.yrtph.2009.05.011

129. Dalenberg JR, Patel BP, Denis R, Veldhuizen MG, Nakamura Y, Vinke PC, et al. Short-term consumption of sucralose with, but not without, carbohydrate impairs neural and metabolic sensitivity to sugar in humans. Cell Metabolism. (2020) 31:493-502.e7. doi: 10.1016/j.cmet.2020.01.014

130. Jeffrey AM, Williams GM. Lack of DNA-damaging activity of five nonnutritive sweeteners in the rat hepatocyte/DNA repair assay. Food Chem Toxicol. (2000) 38:335-8. doi: 10.1016/S0278-6915(99)00163-5

131. Brusick D, Grotz VL, Slesinski R, Kruger CL, Hayes AW. The absence of genotoxicity of sucralose. Food Chem Toxicol. (2010) 48:306772. doi: $10.1016 /$ j.fct.2010.07.047

132. Mann SW, Yuschak MM, Amyes SJG, Aughton P, Finn JP. A combined chronic toxicity/carcinogenicity study of sucralose in Sprague-Dawley rats. Food Chem Toxicol. (2000) 38:71-89. doi: 10.1016/S0278-6915(00) 00029-6

133. Mann SW, Yuschak MM, Amyes SJG, Aughton P, Finn JP. A carcinogenicity study of sucralose in the CD-1 mouse. Food Chem Toxicol. (2000) 38:917. doi: 10.1016/S0278-6915(00)00030-2

134. van Eyk AD. The effect of five artificial sweeteners on Caco2, HT-29 and HEK-293 cells. Drug Chem Toxicol. (2015) 38:318-27. doi: 10.3109/01480545.2014.966381

135. Soffritti M, Padovani M, Tibaldi E, Falcioni L,Manservisi F, Lauriola M, et al. Sucralose administered in feed, beginning prenatally through lifespan, induces hematopoietic neoplasias in male swiss mice. Int J Occup Environ Health. (2016) 22:7-17. doi: 10.1080/10773525.2015.1106075

136. EFSA Panel on Food Additives Nutrient Sources added to Food (ANS), Aguilar F, Crebelli R, Di Domenico A, Dusemund B, Frutos MJ, et al. Statement on the validity of the conclusions of a mouse carcinogenicity study on sucralose (E 955) performed by the Ramazzini Institute. EFSA J. (2017) 15:e04784. doi: 10.2903/j.efsa.2017.4784

137. Fukushima S, Arai M, Nakanowatari J, Hibino T, Okuda M, Ito N. Differences in susceptibility to sodium saccharin among various strains of rats and other animal species. Gan. (1983) 74:8-20.

138. Cohen SM, Fisher MJ, Sakata T, Cano M, Schoenig GP, Chappel CI, et al. Comparative analysis of the proliferative response of the rat urinary bladder to sodium saccharin by light and scanning electron microscopy and autoradiography. Scan Microsc. (1990) 4:135-42.

139. Touyz LZG. Saccharin deemed "not hazardous" in United States and abroad. Curr Oncol. (2011) 18:213-4. doi: 10.3747/co.v18i5.836

140. Azeez OH, Alkass SY, Persike DS. Long-term saccharin consumption and increased risk of obesity, diabetes, hepatic dysfunction, and renal impairment in rats. Medicina. (2019) 55:681. doi: 10.3390/medicina55100681

141. Mukherjee M, Sarkar A. Sugar content in artificial sweetener. Adv Appl Sci Res. (2011) 2:407-9. Available online at: www.pelagiaresearchlibrary.com

142. Di Chiara G, Tanda G, Bassareo V, Pontieri F, Acquas E, Fenu S, et al. Drug addiction as a disorder of associative learning. Role of nucleus accumbens shell/extended amygdala dopamine. Ann N Y Acad Sci. (1999) 877:46185. doi: 10.1111/j.1749-6632.1999.tb09283.x

143. Martel P, Fantino M. Mesolimbic dopaminergic system activity as a function of food reward: a microdialysis study. Pharmacol Biochem Behav. (1996) 53:221-6. doi: 10.1016/0091-3057(95)00187-5

144. Colantuoni C, Rada P, McCarthy J, Patten C, Avena NM, Chadeayne A, et al. Evidence that intermittent, excessive sugar intake causes endogenous opioid dependence. Obes Res. (2002) 10:478-88. doi: 10.1038/oby.2002.66

145. Colantuoni C, Schwenker J, McCarthy J, Rada P, Ladenheim B, Cadet JL, et al. Excessive sugar intake alters binding to dopamine and mu-opioid receptors in the brain. Neuroreport. (2001) 12:3549-52. doi: 10.1097/00001756-200111160-00035

146. Wiss DA, Avena N, Rada P. Sugar addiction: from evolution to revolution. Front Psychiatry. (2018) 9:545. doi: 10.3389/fpsyt.2018.00545

147. Stice E, Spoor S, Bohon C, Small DM. Relation between obesity and blunted striatal response to food is moderated by TaqIA A1 allele. Science. (2008) 322:449-52. doi: 10.1126/science.1161550
148. Kessler RM, Zald DH, Ansari MS, Li R, Cowan RL. Changes in dopamine release and dopamine D2/3 receptor levels with the development of mild obesity. Synapse. (2014) 68:317-20. doi: 10.1002/syn.21738

149. Volkow ND, Wang G-J, Fowler JS, Telang F. Overlapping neuronal circuits in addiction and obesity: evidence of systems pathology. Philos T R SOC B. (2008) 363:3191-200. doi: 10.1098/rstb.2008. 0107

150. Wang G-J, Volkow ND, Thanos PK, Fowler JS. Similarity between obesity and drug addiction as assessed by neurofunctional imaging: a concept review. J Addict Dis. (2004) 23:39-53. doi: 10.1300/J069v23n03_04

151. Wang GJ, Volkow ND, Logan J, Pappas NR, Wong CT, Zhu W, et al. Brain dopamine and obesity. Lancet. (2001) 357:354-7. doi: 10.1016/S0140-6736(00)03643-6

152. Feng Zhao, Noll DC, Nielsen J-F, Fessler JA. Separate magnitude and phase regularization via compressed sensing. IEEE Trans Med Imaging. (2012) 31:1713-23. doi: 10.1109/TMI.2012.2196707

153. Kelley AE, Berridge KC. The neuroscience of natural rewards: relevance to addictive drugs. J Neurosci. (2002) 22:330611. doi: 10.1523/JNEUROSCI.22-09-03306.2002

154. Bassareo V, Di Chiara G. Modulation of feeding-induced activation of mesolimbic dopamine transmission by appetitive stimuli and its relation to motivational state. Eur J Neurosci. (1999) 11:4389-97. doi: 10.1046/j.1460-9568.1999.00843.x

155. Pothos E, Rada P, Mark GP, Hoebel BG. Dopamine microdialysis in the nucleus accumbens during acute and chronic morphine, naloxoneprecipitated withdrawal and clonidine treatment. Brain Res. (1991) 566:34850. doi: 10.1016/0006-8993(91)91724-F

156. Brunstrom JM, Mitchell GL. Flavor-nutrient learning in restrained and unrestrained eaters. Physiol Behav. (2007) 90:133-41. doi: 10.1016/j.physbeh.2006.09.016

157. Smeets PAM, Erkner A, de Graaf C. Cephalic phase responses and appetite. Nutr Rev. (2010) 68:643-55. doi: 10.1111/j.1753-4887.2010.00334.x

158. Kosse C, Gonzalez A, Burdakov D. Predictive models of glucose control: roles for glucose-sensing neurones. Acta Physiol. (2015) 213:718. doi: 10.1111/apha. 12360

159. Teff KL. How neural mediation of anticipatory and compensatory insulin release helps us tolerate food. Physiol Behav. (2011) 103:4450. doi: 10.1016/j.physbeh.2011.01.012

160. Glendinning JI, Stano S, Holter M, Azenkot T, Goldman O, Margolskee RF, et al. Sugar-induced cephalic-phase insulin release is mediated by a T1r2+T1r3-independent taste transduction pathway in mice. Am J Physiol Regul Integr Comp Physiol. (2015) 309:R552-60. doi: 10.1152/ajpregu.00056.2015

161. Burke MV, Small DM. Physiological mechanisms by which non-nutritive sweeteners may impact body weight and metabolism. Physiol Behav. (2015) 152(Pt. B):381-8. doi: 10.1016/j.physbeh.2015.05.036

162. de Araujo IE, Oliveira-Maia AJ, Sotnikova TD, Gainetdinov RR, Caron MG, Nicolelis MAL, et al. Food reward in the absence of taste receptor signaling. Neuron. (2008) 57:930-41. doi: 10.1016/j.neuron.2008.01.032

163. Swithers SE. Artificial sweeteners produce the counterintuitive effect of inducing metabolic derangements. Trends Endocrinol Metab. (2013) 24:43141. doi: 10.1016/j.tem.2013.05.005

164. Frank GKW, Oberndorfer TA, Simmons AN, Paulus MP, Fudge JL, Yang TT, et al. Sucrose activates human taste pathways differently from artificial sweetener. Neuroimage. (2008) 39:1559-69. doi: 10.1016/j.neuroimage.2007.10.061

165. Domingos AI, Sordillo A, Dietrich MO, Liu Z-W, Tellez LA, Vaynshteyn J, et al. Hypothalamic melanin concentrating hormone neurons communicate the nutrient value of sugar. Elife. (2013) 2:e01462. doi: 10.7554/eLife.01462

166. Glendinning JI. Do low-calorie sweeteners promote weight gain in rodents? Physiol Behav. (2016) 164:509-13. doi: 10.1016/j.physbeh.2016.01.043

167. Schulze MB, Manson JE, Ludwig DS, Colditz GA, Stampfer MJ, Willett WC, et al. Sugar-sweetened beverages, weight gain, and incidence of type 2 diabetes in young and middle-aged women. JAMA. (2004) 292:92734. doi: 10.1001/jama.292.8.927

168. Pereira MA. Sugar-sweetened and artificially-sweetened beverages in relation to obesity risk. Adv Nutr. (2014) 5:797-808. doi: 10.3945/an.114.007062 
169. Blum JW, Jacobsen DJ, Donnelly JE. Beverage consumption patterns in elementary school aged children across a two-year period. J Am Coll Nutr. (2005) 24:93-8. doi: 10.1080/07315724.2005.107 19449

170. Rogers PJ, Hogenkamp PS, de Graaf C, Higgs S, Lluch A, Ness AR, et al. Does low-energy sweetener consumption affect energy intake and body weight? A systematic review, including meta-analyses, of the evidence from human and animal studies. Int J Obes. (2016) 40:381-94. doi: 10.1038/ijo.2015.177

171. Miller PE, Perez V. Low-calorie sweeteners and body weight and composition: a meta-analysis of randomized controlled trials and prospective cohort studies. Am J Clin Nutr. (2014) 100:765-77. doi: 10.3945/ajen.113.082826

172. Sylvetsky AC, Blau JE, Rother KI. Understanding the metabolic and health effects of low-calorie sweeteners: methodological considerations and implications for future research. Rev Endocr Metab Disord. (2016) 17:18794. doi: 10.1007/s11154-016-9344-5

173. Nelson G, Hoon MA, Chandrashekar J, Zhang Y, Ryba NJ, Zuker CS. Mammalian sweet taste receptors. Cell. (2001) 106:381-90. doi: 10.1016/S0092-8674(01)00451-2

174. Chaudhari N, Roper SD. The cell biology of taste. J Cell Biol. (2010) 190:28596. doi: $10.1083 /$ jcb.201003144

175. Roper SD, Chaudhari N. Taste buds: cells, signals and synapses. Nat Rev Neurosci. (2017) 18:485-97. doi: 10.1038/nrn.2017.68

176. Chandrashekar J, Hoon MA, Ryba NJP, Zuker CS. The receptors and cells for mammalian taste. Nature. (2006) 444:288-94. doi: 10.1038/nature05401

177. Steinert RE, Gerspach AC, Gutmann H, Asarian L, Drewe J, Beglinger C. The functional involvement of gut-expressed sweet taste receptors in glucosestimulated secretion of glucagon-like peptide-1 (GLP-1) and peptide YY (PYY). Clin Nutr. (2011) 30:524-32. doi: 10.1016/j.clnu.2011.01.007

178. Fujita Y, Wideman RD, Speck M, Asadi A, King DS, Webber TD, et al. Incretin release from gut is acutely enhanced by sugar but not by sweeteners in vivo. Am J Physiol Endocrinol Metab. (2009) 296:E4739. doi: 10.1152/ajpendo.90636.2008

179. Nakagawa Y, Nagasawa M, Yamada S, Hara A, Mogami H, Nikolaev VO, et al. Sweet taste receptor expressed in pancreatic beta-cells activates the calcium and cyclic AMP signaling systems and stimulates insulin secretion. PLoS ONE. (2009) 4:e5106. doi: 10.1371/journal.pone.0005106

180. Toyono T, Seta Y, Kataoka S, Toyoshima K. CCAAT/Enhancer-binding protein beta regulates expression of human T1R3 taste receptor gene in the bile duct carcinoma cell line, HuCCT1. Biochim Biophys Acta. (2007) 1769:641-8. doi: 10.1016/j.bbaexp.2007.08.003

181. Finger TE, Kinnamon SC. Taste isn't just for taste buds anymore. F1000 Biol Rep. (2011) 3:20. doi: 10.3410/B3-20

182. Margolskee RF, Dyer J, Kokrashvili Z, Salmon KSH, Ilegems E, Daly K, et al. T1R3 and gustducin in gut sense sugars to regulate expression of $\mathrm{Na}+$-glucose cotransporter 1. Proc Natl Acad Sci USA. (2007) 104:1507580. doi: $10.1073 /$ pnas. 0706678104

183. Ghatei MA, Uttenthal LO, Christofides ND, Bryant MG, Bloom SR. Molecular forms of human enteroglucagon in tissue and plasma: plasma responses to nutrient stimuli in health and in disorders of the upper gastrointestinal tract. J Clin Endocrinol Metab. (1983) 57:48895. doi: $10.1210 /$ jcem-57-3-488

184. Jang H-J, Kokrashvili Z, Theodorakis MJ, Carlson OD, Kim B-J, Zhou $\mathrm{J}$, et al. Gut-expressed gustducin and taste receptors regulate secretion of glucagon-like peptide-1. Proc Natl Acad Sci USA. (2007) 104:1506974. doi: $10.1073 /$ pnas. 0706890104

185. Ford HE, Peters V, Martin NM, Sleeth ML, Ghatei MA, Frost GS, et al. Effects of oral ingestion of sucralose on gut hormone response and appetite in healthy normal-weight subjects. Eur J Clin Nutr. (2011) 65:50813. doi: $10.1038 /$ ejen.2010.291

186. Steinert RE, Frey F, Töpfer A, Drewe J, Beglinger C. Effects of carbohydrate sugars and artificial sweeteners on appetite and the secretion of gastrointestinal satiety peptides. Br J Nutr. (2011) 105:13208. doi: $10.1017 /$ S000711451000512X

187. Wu T, Zhao BR, Bound MJ, Checklin HL, Bellon M, Little TJ, et al. Effects of different sweet preloads on incretin hormone secretion, gastric emptying, and postprandial glycemia in healthy humans. Am J Clin Nutr. (2012) 95:78-83. doi: 10.3945/ajcn.111.021543
188. Brown RJ, Walter M, Rother KI. Ingestion of diet soda before a glucose load augments glucagon-like peptide-1 secretion. Diabetes Care. (2009) 32:21846. doi: $10.2337 / \mathrm{dc} 09-1185$

189. Mace OJ, Affleck J, Patel N, Kellett GL. Sweet taste receptors in rat small intestine stimulate glucose absorption through apical GLUT2. J Physiol. (2007) 582(Pt. 1):379-92. doi: 10.1113/jphysiol.2007.130906

190. Abudula R, Matchkov VV, Jeppesen PB, Nilsson H, Aalkjaer C, Hermansen K. Rebaudioside A directly stimulates insulin secretion from pancreatic beta cells: a glucose-dependent action via inhibition of ATP-sensitive K-channels. Diabetes Obes Metab. (2008) 10:1074-85. doi: 10.1111/j.1463-1326.2008.00864.x

191. Abudula R, Jeppesen PB, Rolfsen SED, Xiao J, Hermansen K. Rebaudioside A potently stimulates insulin secretion from isolated mouse islets: studies on the dose-, glucose-, and calcium-dependency. Metab Clin Exp. (2004) 53:1378-81. doi: 10.1016/j.metabol.2004.04.014

192. Gregersen S, Jeppesen PB, Holst JJ, Hermansen K. Antihyperglycemic effects of stevioside in type 2 diabetic subjects. Metab Clin Exp. (2004) 53:736. doi: 10.1016/j.metabol.2003.07.013

193. Turnbaugh PJ, Bäckhed F, Fulton L, Gordon JI. Diet-induced obesity is linked to marked but reversible alterations in the mouse distal gut microbiome. Cell Host Microbe. (2008) 3:213-23. doi: 10.1016/j.chom.2008.02.015

194. Di Rienzi SC, Britton RA. Adaptation of the gut microbiota to modern dietary sugars and sweeteners. Adv Nutr. (2019) 11:616-29. doi: 10.1093/advances/nmz118

195. Zoetendal EG, Raes J, van den Bogert B, Arumugam M, Booijink CCGM, Troost FJ, et al. The human small intestinal microbiota is driven by rapid uptake and conversion of simple carbohydrates. ISME J. (2012) 6:141526. doi: 10.1038/ismej.2011.212

196. Donaldson GP, Lee SM, Mazmanian SK. Gut biogeography of the bacterial microbiota. Nat Rev Microbiol. (2016) 14:20-32. doi: 10.1038/nrmicro 3552

197. Suez J, Korem T, Zeevi D, Zilberman-Schapira G, Thaiss CA, Maza O, et al. Artificial sweeteners induce glucose intolerance by altering the gut microbiota. Nature. (2014) 514:181-6. doi: 10.1038/nature13793

198. Anderson RL, Kirkland JJ. The effect of sodium saccharin in the diet on caecal microflora. Food Cosmet Toxicol. (1980) 18:353-5. doi: 10.1016/0015-6264(80)90188-1

199. Pfeffer M, Ziesenitz SC, Siebert G. Acesulfame K, cyclamate and saccharin inhibit the anaerobic fermentation of glucose by intestinal bacteria. $Z$ Ernahrungswiss. (1985) 24:231-5. doi: 10.1007/BF02023668

200. Petersen C, Round JL. Defining dysbiosis and its influence on host immunity and disease. Cell Microbiol. (2014) 16:1024-33. doi: 10.1111/cmi.12308

201. Bian X, Tu P, Chi L, Gao B, Ru H, Lu K. Saccharin induced liver inflammation in mice by altering the gut microbiota and its metabolic functions. Food Chem Toxicol. (2017) 107(Pt. B):530-9. doi: 10.1016/j.fct.2017. 04.045

202. Sousa A, Ramiro RS, Barroso-Batista J, Güleresi D, Lourenço M, Gordo I. Recurrent reverse evolution maintains polymorphism after strong bottlenecks in commensal gut bacteria. Mol Biol Evol. (2017) 34:287992. doi: $10.1093 / \mathrm{molbev} / \mathrm{msx} 221$

203. Mäkinen KK. Biochemical principles of the use of xylitol in medicine and nutrition with special consideration of dental aspects. Exp Suppl. (1978) 30:1-160. doi: 10.1007/978-3-0348-5757-4

204. Denina I, Semjonovs P, Fomina A, Treimane R, Linde R. The influence of Stevia glycosides on the growth of Lactobacillus reuteri strains. Lett Appl Microbiol. (2014) 58:278-84. doi: 10.1111/lam.12187

205. Sanches Lopes SM, Francisco MG, Higashi B, de Almeida RTR, Krausová G, Pilau EJ, et al. Chemical characterization and prebiotic activity of fructo-oligosaccharides from Stevia rebaudiana (Bertoni) roots and in vitro adventitious root cultures. Carbohydr Polym. (2016) 152:71825. doi: 10.1016/j.carbpol.2016.07.043

206. Tomita T, Sato N, Arai T, Shiraishi H, Sato M, Takeuchi M, et al. Bactericidal activity of a fermented hot-water extract from stevia rebaudiana bertoni towards enterohemorrhagic Escherichia coli O157:H7 and other food-borne pathogenic bacteria. Microbiol Immunol. (1997) 41:10059. doi: 10.1111/j.1348-0421.1997.tb01961.x

207. Peuranen S, Tiihonen K, Apajalahti J, Kettunen A, Saarinen M, Rautonen N. Combination of polydextrose and lactitol affects microbial ecosystem and 
immune responses in rat gastrointestinal tract. Br J Nutr. (2004) 91:90514. doi: 10.1079/BJN20041114

208. Beards E, Tuohy K, Gibson G. A human volunteer study to assess the impact of confectionery sweeteners on the gut microbiota composition. Br J Nutr. (2010) 104:701-8. doi: 10.1017/S0007114510001078

209. Uebanso T, Kano S, Yoshimoto A, Naito C, Shimohata T, Mawatari K, et al. Effects of consuming xylitol on gut microbiota and lipid metabolism in Mice. Nutrients. (2017) 9:756. doi: 10.3390/nu9070756

210. Salminen S, Salminen E, Koivistoinen P, Bridges J, Marks V. Gut microflora interactions with xylitol in the mouse, rat and man. Food Chem Toxicol. (1985) 23:985-90. doi: 10.1016/0278-6915(85)90248-0

211. Richards AB, Krakowka S, Dexter LB, Schmid H, Wolterbeek APM, Waalkens-Berendsen DH, et al. Trehalose: a review of properties, history of use and human tolerance, and results of multiple safety studies. Food Chem Toxicol. (2002) 40:871-98. doi: 10.1016/S0278-6915(02)00011-X

212. Shimokawa C, Kato T, Takeuchi T, Ohshima N, Furuki T, Ohtsu Y, et al. $\mathrm{CD} 8+$ regulatory $\mathrm{T}$ cells are critical in prevention of autoimmune-mediated diabetes. Nat Commun. (2020) 11:1922. doi: 10.1038/s41467-020-15857-x

213. Pope E, Koren G, Bozzo P. Sugar substitutes during pregnancy. Can Fam Phys. (2014) 60:1003-5.

214. Sylvetsky AC, Gardner AL, Bauman V, Blau JE, Garraffo HM, Walter PJ, et al. Nonnutritive sweeteners in breast milk. J Toxicol Environ Health A. (2015) 78:1029-32. doi: 10.1080/15287394.2015.1053646

215. Zhang G-H, Chen M-L, Liu S-S, Zhan Y-H, Quan Y, Qin Y-M, et al. Effects of mother's dietary exposure to acesulfame-k in pregnancy or lactation on the adult offspring's sweet preference. Chem Senses. (2011) 36:76370. doi: 10.1093/chemse/bjr050

216. Kille JW, Tesh JM, McAnulty PA, Ross FW, Willoughby CR, Bailey GP, et al. Sucralose: assessment of teratogenic potential in the rat and the rabbit. Food Chem Toxicol. (2000) 38(Suppl. 2):S43-52. doi: 10.1016/S0278-6915(00)00027-2

217. Azad MB, Archibald A, Tomczyk MM, Head A, Cheung KG, de Souza RJ, et al. Nonnutritive sweetener consumption during pregnancy, adiposity, and adipocyte differentiation in offspring: evidence from humans, mice, and cells. Int J Obes. (2020). doi: 10.1038/s41366-020-0575-x. [Epub ahead of print].

218. Olivier-Van Stichelen S, Rother KI, Hanover JA. Maternal exposure to nonnutritive sweeteners impacts progeny's metabolism and microbiome. Front Microbiol. (2019) 10:1360. doi: 10.3389/fmicb.2019.01360

219. Food Standards Agency. Current EU Approved Additives and Their E Numbers (2016).

220. Serra-Majem L, Raposo A, Aranceta-Bartrina J, Varela-Moreiras G, Logue $\mathrm{C}$, Laviada $\mathrm{H}$, et al. Ibero-American consensus on low- and no-calorie sweeteners: safety, nutritional aspects and benefits in food and beverages. Nutrients. (2018) 10:818. doi: 10.3390/nu10070818

221. Roberts A. The safety and regulatory process for low calorie sweeteners in the United States. Physiol Behav. (2016) 164:43944. doi: 10.1016/j.physbeh.2016.02.039

222. Guidance for Submission for Food Additive Evaluations. European Food Safety Authority (EFSA) EFSA Panel on Food Additives and Nutrient Sources Added to Food (2012).
223. Gibson S, Drewnowski A, Hill J, Raben AB, Tuorila H, Widström E. Consensus statement on benefits of low-calorie sweeteners: benefits of lowcalorie sweeteners. Nutr Bull. (2014) 39:386-9. doi: 10.1111/nbu.12116

224. Gupta P, Gupta N, Pawar AP, Birajdar SS, Natt AS, Singh HP. Role of sugar and sugar substitutes in dental caries: a review. ISRN Dent. (2013) 2013:519421. doi: 10.1155/2013/519421

225. Gibson S, Horgan G, Francis L, Gibson A, Stephen A. Low calorie beverage consumption is associated with energy and nutrient intakes and diet quality in British adults. Nutrients. (2016) 8:9. doi: 10.3390/nu8010009

226. La Vecchia C. Intake of artificially sweetened soft drinks and risk of preterm delivery. Am J Clin Nutr. (2010) 92:1540. doi: 10.3945/ajcn.110.003566

227. Johnson RK, Lichtenstein AH, Anderson CAM, Carson JA, Després J-P, Hu $\mathrm{FB}$, et al. Low-calorie sweetened beverages and cardiometabolic health: a science advisory from the American Heart association. Circulation. (2018) 138:e126-40. doi: 10.1161/CIR.0000000000000569

228. Ruanpeng D, Thongprayoon C, Cheungpasitporn W, Harindhanavudhi T. Sugar and artificially sweetened beverages linked to obesity: a systematic review and meta-analysis. QJM. (2017) 110:51320. doi: 10.1093/qjmed/hcx068

229. O’Connor L, Imamura F, Lentjes MAH, Khaw K-T, Wareham NJ, Forouhi NG. Prospective associations and population impact of sweet beverage intake and type 2 diabetes, and effects of substitutions with alternative beverages. Diabetologia. (2015) 58:1474-83. doi: 10.1007/s00125-015-3572-1

230. Pearlman M, Obert J, Casey L. The association between artificial sweeteners and obesity. Curr Gastroenterol Rep. (2017) 19:64. doi: 10.1007/s11894-017-0602-9

231. Caprio M, Infante M, Moriconi E, Armani A, Fabbri A, Mantovani G, et al. Very-low-calorie ketogenic diet (VLCKD) in the management of metabolic diseases: systematic review and consensus statement from the Italian Society of Endocrinology (SIE). J Endocrinol Invest. (2019) 42:13651386. doi: 10.1007/s40618-019-01061-2

232. Danneskiold-Samsøe NB, Dias de Freitas Queiroz Barros H, Santos R, Bicas JL, Cazarin CBB, Madsen L, et al. Interplay between food and gut microbiota in health and disease. Food Res Int. (2019) 115:2331. doi: 10.1016/j.foodres.2018.07.043

233. Rother KI, Conway EM, Sylvetsky AC. How non-nutritive sweeteners influence hormones and health. Trends Endocrinol Metab. (2018) 29:45567. doi: 10.1016/j.tem.2018.04.010

Conflict of Interest: The authors declare that the research was conducted in the absence of any commercial or financial relationships that could be construed as a potential conflict of interest.

Copyright (c) 2020 Moriconi, Feraco, Marzolla, Infante, Lombardo, Fabbri and Caprio. This is an open-access article distributed under the terms of the Creative Commons Attribution License (CC BY). The use, distribution or reproduction in other forums is permitted, provided the original author(s) and the copyright owner(s) are credited and that the original publication in this journal is cited, in accordance with accepted academic practice. No use, distribution or reproduction is permitted which does not comply with these terms. 